\title{
Syntaxin Modulation of Slow Inactivation of N-Type Calcium Channels
}

\author{
Vadim E. Degtiar, ${ }^{1}$ Richard H. Scheller, ${ }^{1,2}$ and Richard W. Tsien ${ }^{1}$ \\ ${ }^{1}$ Department of Molecular and Cellular Physiology, Beckman Center, and ${ }^{2 H o w a r d}$ Hughes Medical Institute, Stanford \\ University School of Medicine, Stanford, California 94305
}

Syntaxin, a membrane protein vital in triggering vesicle fusion, interacts with voltage-gated $\mathrm{N}$ - and $\mathrm{P} / \mathrm{Q}$-type $\mathrm{Ca}^{2+}$ channels. This biochemical association is proposed to colocalize $\mathrm{Ca}^{2+}$ channels and presynaptic release sites, thus supporting rapid and efficient initiation of neurotransmitter release. The syntaxin channel interaction may also support a novel signaling function, to modulate $\mathrm{Ca}^{2+}$ channels according to the state of the associated release machinery (Bezprozvanny et al., 1995; Wiser et al., 1996; see also Mastrogiacomo et al., 1994). Here we report that syntaxin 1A (syn1A) coexpressed with $\mathrm{N}$-type channels in Xenopus oocytes greatly promoted slow inactivation gating, but had little or no effect on the onset of and recovery from fast inactivation. Accordingly, the effectiveness of syntaxin depended strongly on voltage protocol. Slow inactivation was found for $\mathrm{N}$-type channels even in the absence of syntaxin and could be distinguished from fast inactivation on the basis of its slow kinetics, distinct voltage dependence (voltage-independent at potentials higher than the level of half-inactivation), and temperature independence $\left(Q_{10}, \sim 0.8\right)$. Trains of action potential-like stimuli were more effective than steady depolarizations in stabilizing the slowly inactivated condition. Agents that stimulate protein kinase $\mathrm{C}$ decreased the inhibitory effect of syntaxin on N-type channels. Application of BoNtC1 to cleave syntaxin sharply attenuated the modulatory effects on $\mathrm{Ca}^{2+}$ channel gating, consistent with structural analysis of syntaxin modulation, supporting use of this toxin to test for the impact of syntaxin on $\mathrm{Ca}^{2+}$ influx in nerve terminals.

Key words: N-type calcium channels; syntaxin; slow inactivation; channel gating; botulinum neurotoxin
The plasma membrane protein syntaxin 1A (syn1A) is a critical element of the presynaptic machinery controlling the release of neurotransmitter vesicles from presynaptic terminals (Bennett et al., 1992; Yoshida et al., 1992). It engages in prolific yet specific interactions with key membrane-associated proteins of both plasmalemmal and vesicular membranes, including VAMP, SNAP25 , and synaptotagmin, thereby participating in vesicle fusion (DeBello et al., 1995; Sudhof, 1995; Hanson et al., 1997). Considerable attention has been devoted to the interaction of syntaxin with voltage-gated $\mathrm{Ca}^{2+}$ channels specifically involved in triggering neurotransmitter release. Biochemical association with syntaxin has been demonstrated for N-type $\left(\alpha_{1 \mathrm{~B}}\right)$ and P/Q-type $\left(\alpha_{1 \mathrm{~A}}\right)$ channels (Leveque et al., 1994; Sheng et al., 1994), the channel types most critical for synaptic transmission at CNS synapses (Takahashi and Momiyama, 1993; Turner et al., 1993, 1995; Castillo et al., 1994; Wheeler et al., 1994). It has been proposed that syntaxin may help colocalize these $\mathrm{Ca}^{2+}$ channels with presynaptic release sites, thus positioning $\mathrm{Ca}^{2+}$ entry where it can trigger exocytosis rapidly and efficiently. An additional possibility, intriguing but less well established, is that the syntaxin channel interaction supports a novel signaling function, to modify $\mathrm{Ca}^{2+}$ channel gating, possibly according to the state of any

Received June 22, 1999; revised Dec. 23, 1999; accepted March 14, 2000.

This work was supported by the Silvio Conte-National Institute of Mental Health Center for Neuroscience Research, the Mathers Charitable Trust, and the McKnight Foundation.

Correspondence should be addressed to Dr. Richard W. Tsien, Department of Molecular and Cellular Physiology, Beckman Center B105, Stanford Medical Center, Stanford, CA 94305-5345. E-mail: rwtsien@leland.stanford.edu.

Dr. Degtiar's present address: Department of General Physiology of The Nervous System, Bogomoletz Institute of Physiology, Bogomoletz Street 4, Kiev 01024, Ukraine.

Copyright (C) 2000 Society for Neuroscience $\quad 0270-6474 / 00 / 204355-13 \$ 15.00 / 0$ associated release machinery (Mastrogiacomo et al., 1994; Bezprozvanny et al., 1995; Wiser et al., 1996; Nie et al., 1999). The impetus for proposing a nonconventional role for syntaxin came from expression studies in which syntaxin strongly promoted the inactivation of $\mathrm{N}$ - and $\mathrm{P} / \mathrm{Q}$-type channels in Xenopus oocytes (Bezprozvanny et al., 1995; Wiser et al., 1996). Likewise, overexpression of syntaxin decreases $\mathrm{Ca}^{2+}$ channel current in Aplysia neurons (Smirnova et al., 1995). According to this hypothesis, syntaxin-mediated changes in $\mathrm{Ca}^{2+}$ channel activity would represent the final step in a pathway for feedback communication, distinct from the classical signaling mechanism by which $\mathrm{Ca}^{2+}$ triggers release (Katz and Miledi, 1965; Douglas, 1968; Katz, 1969).

This is the first in a series of papers that focus on the modulatory interaction between syntaxin and $\mathrm{Ca}^{2+}$ channels and several outstanding questions about its functional implications. One of the most fundamental issues concerns the nature of the effects of syntaxin on $\mathrm{Ca}^{2+}$ channel inactivation. Although previous experiments have shown that syntaxin decreases the availability of $\mathrm{Ca}^{2+}$ channels in a manner that can be overcome by strong hyperpolarization (Bezprozvanny et al., 1995; Wiser et al., 1996), considerable uncertainty remains about the kinetic aspects of the modulation. A major obstacle was the inherent complexity of the inactivation of $\mathrm{N}$-type $\mathrm{Ca}^{2+}$ channels, which is known to proceed in multiple phases, extending over periods ranging from tens of milliseconds to many minutes (Jones and Marks, 1989; Stocker et al., 1997; Patil et al., 1998). In this study, we performed a detailed analysis of the modulatory effect of syntaxin, taking these kinetic complexities into account. Our experiments revealed a remarkable selectivity of syntaxin in promoting "slow inactivation" rather than "fast inactivation". We found that the syntaxin- 
stabilized slow inactivated state can be preferentially accessed with even mild depolarizations, in the range of typical resting potentials in neuronal systems or by trains of brief depolarizations similar to those imposed by tetanic stimulation. The modulatory effect was significantly attenuated by toxin-mediated cleavage of expressed syntaxin or by protein kinase $\mathrm{C}$ stimulation. These findings set the stage for a systematic exploration of molecular determinants of the syntaxin- $\mathrm{Ca}^{2+}$ channel signaling (Bezprozvanny et al., 2000) and provided a foundation for experiments to define the impact of the modulation of syntaxin on $\mathrm{Ca}^{2+}$ influx in isolated nerve terminals (Bergsman and Tsien, 2000).

Preliminary versions of this paper have been presented in abstract form (Bergsman and Tsien, 1996; Degtiar et al., 1997).

\section{MATERIALS AND METHODS}

Single frog oocytes (Xenopus laevis) were obtained by treatment of ovarian tissue with $2 \mathrm{mg} / \mathrm{ml}$ collagenase A (Boehringer Mannheim, Mannheim, Germany) for $2 \mathrm{hr}$ in OR-2 solution (in mM: $82.5 \mathrm{NaCl}, 2$ $\mathrm{KCl}, 1 \mathrm{MgCl}_{2}$, and $5 \mathrm{HEPES}, \mathrm{pH} 7.5$ ). After this treatment, oocytes were washed in OR-2 then transferred to ND96 medium (in mM: $96 \mathrm{NaCl}, 2$ $\mathrm{KCl}, 1.8 \mathrm{CaCl}_{2}, 1 \mathrm{MgCl}_{2}$, and 5 HEPES, $\mathrm{pH}$ 7.6) that had been supplemented with $2.5 \mathrm{~mm}$ sodium pyruvate and antibiotics. Oocytes were kept at $18^{\circ} \mathrm{C}$ for $1 \mathrm{~d}$ before cRNA injection.

RNA species were synthesized by in vitro transcription procedures using T7 and SP6 polymerases in the presence of the cap analog $\mathrm{G}\left(5^{\prime}\right) \mathrm{ppp}\left(5^{\prime}\right) \mathrm{G}$ (Pharmacia, Piscataway, $\mathrm{NJ}$ ) and a mixture of ribonucleotides, and dissolved in water. For channel expression, cRNA species encoding human $\alpha_{1 \mathrm{~B}}$ (Ellinor et al., 1994), rabbit $\beta_{3}$ (Hullin et al., 1992), and rabbit $\alpha_{2} / \delta$ subunits (courtesy of Prof. T. Tanabe) were mixed in a molar ratio of $\sim 1: 2: 2$. The average injected volume was $50 \mathrm{nl}$, corresponding to 0.6:0.45:0:6 ng cRNA per oocyte. Injected oocytes were held at $18^{\circ} \mathrm{C}$ for $4-5 \mathrm{~d}$, then reinjected with an aliquot of solution containing cRNA encoding syn1A (Bennett et al., 1992) subcloned in the pGEMHE expression vector ( $\sim 20 \mathrm{ng} /$ oocyte) or an equal volume of water (control). In some experiments, the same quantity of syn1A cRNA was mixed and coinjected with cRNA encoding the $\mathrm{Ca}^{2+}$ channel subunits $(3: 2: 3 \mathrm{ng} /$ oocyte). When cRNAs encoding syn1A and calcium channel subunits were injected simultaneously, there was a prominent decrease in calcium channel current amplitude, even when hyperpolarized holding potentials were used to reverse slow inactivation (Bezprozvanny et al., 1995). We interpret this reduction in terms of altered synthesis or processing of calcium channels caused by an excess of coexpressed syntaxin transcript or protein. If the syn1A RNA was injected 4-5 d after injection of $\mathrm{Ca}$ channel subunit cRNAs, as in the bulk of our experiments, no significant reduction of maximal current amplitude was observed after syntaxin coexpression.

Botulinum toxin $\mathrm{C} 1$ (BoNtC1; Calbiochem, La Jolla, CA) light chain was injected into oocytes (50 $\mathrm{nl}$ of $100 \mathrm{~nm}$ solution) 3-6 hr before measurements. The reduced form of $\mathrm{BoNtC} 1$ was prepared by incubating it with DTT $(5 \mathrm{~mm})$ for $1.5 \mathrm{hr}$ at $37^{\circ} \mathrm{C}$. As an alternative approach, BoNtC1 was applied externally (200 nM in ND96) for 10-18 hr before current measurements.

$\mathrm{Ba}^{2+}$ currents through $\mathrm{Ca}^{2+}$ channels $\left(I_{\mathrm{Ba}}\right)$ were recorded with a two-microelectrode voltage clamp (Warner amplifier OC-725A), 3-10 d after the second cRNA injection. Recordings were performed at room temperature $\left(23-25^{\circ} \mathrm{C}\right)$, unless otherwise specified. For experiments at $35^{\circ} \mathrm{C}$, temperature was controlled with a model $5000 \mathrm{KT}$ stage $(20 / 20$ Technology, Whitehouse Station, NJ).

The bathing medium was a chloride-free solution containing $5 \mathrm{~mm}$ $\mathrm{Ba}(\mathrm{OH})_{2}, 85 \mathrm{~mm}$ TEA-OH, $2 \mathrm{~mm} \mathrm{KOH}, 5 \mathrm{~mm}$ HEPES, $\mathrm{pH}$ adjusted to 7.4 with methanesulphonic acid, connected to a virtual ground amplifier via a $3 \mathrm{M} \mathrm{KCl}$-agar bridge. The microelectrodes were filled with $3 \mathrm{M} \mathrm{KCl}$ and had resistances in the range of $0.4-1.5 \mathrm{M} \Omega$.

In many experimental protocols designed to measure the kinetics of onset of inactivation or recovery from inactivation, individual trials were preceded by a long period at a holding potential of $-120 \mathrm{mV}$. In this way, channels were allowed to recover completely from inactivation between trials and comparable conditions for repeated measurements were achieved.

For comparison of current kinetics under different conditions, we used recordings in which $I_{\mathrm{Ba}}$ amplitudes were comparable (in the range of
Control

A

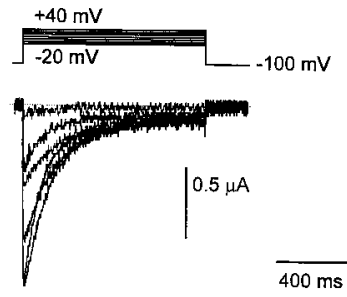

B

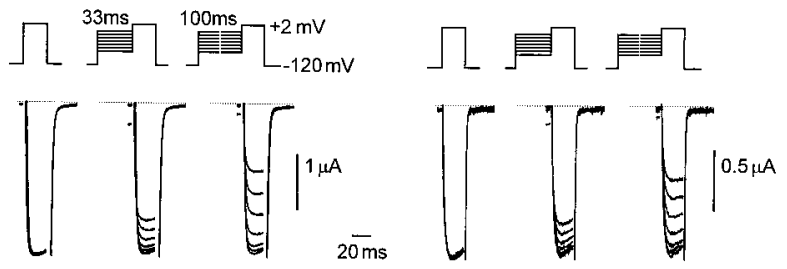

C

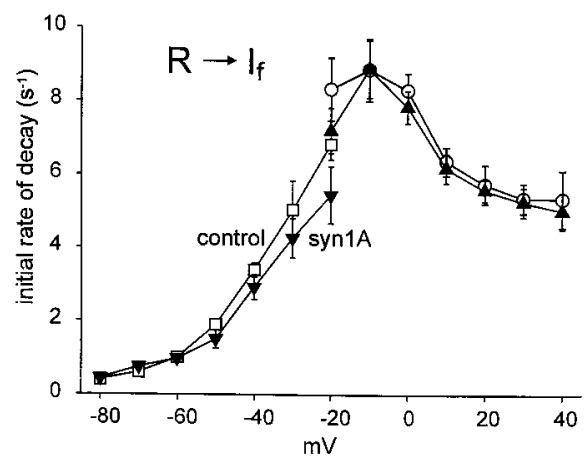

Figure 1. Effect of syntaxin on fast inactivation of $\mathrm{N}$-type $\mathrm{Ca}^{2+}$ channels. $A, I_{\mathrm{Ba}}$ traces in a control oocyte (left) and in one expressing syn1A (right), elicited every $45 \mathrm{sec}$ from a holding potential $\left(V_{\mathrm{h}}\right)$ of $-100 \mathrm{mV}$ (test pulse protocol is shown above the current traces). Leak current subtracted with $\mathrm{P} / 4$ protocol. $B, I_{\mathrm{Ba}}$ inactivation produced by short voltage prepulses (33 and $100 \mathrm{msec}$ ) below the threshold for significant $I_{\mathrm{Ba}}$ activation. Prepulses to various potentials between -80 and $-20 \mathrm{mV}$ were initiated from $V_{\mathrm{h}}$ of $-120 \mathrm{mV}(50 \mathrm{sec}$ between consecutive measurements). $C$, Initial rate of $I_{\mathrm{Ba}}$ inactivation at different membrane potentials in control (open symbols) and with syn1A ( filled symbols). For potentials between -20 and $+40 \mathrm{mV}$, initial rate was determined by direct exponential fit to current traces over the period between 30 and $100 \mathrm{msec}$ using the expression $I(t) / I(30 \mathrm{msec})=\exp (-\mathrm{kt})$; data given as mean $\pm \mathrm{SEM}$ $(n=11-12)$. For potentials at or negative to $-20 \mathrm{mV}$, initial rate was determined by decrease of $I_{\mathrm{Ba}}$ after $33 \mathrm{msec}$ prepulses, assuming an exponential decay $(n=4-7)$. The reaction denoted here $\left(R \rightarrow I_{\mathrm{f}}\right)$, and similar schema in other figures, convey the type of gating transition under study without commitment to a precise reaction scheme.

0.85-2.7 $\mu \mathrm{A}$ ). The pClamp 6.0 software package (Axon Instruments, Foster City, CA) was used for data acquisition and analysis. Data are given as mean \pm SEM.

\section{RESULTS}

\section{Influence of syntaxin on different aspects of inactivation of $\mathrm{N}$-type $\mathrm{Ca}^{2+}$ channels}

We studied the effects of exogenous syntaxin on the kinetic properties of $\mathrm{N}$-type $\mathrm{Ca}^{2+}$ channels expressed in Xenopus oocytes. $\mathrm{Ca}^{2+}$ channel currents were recorded under twomicroelectrode voltage clamp, with $\mathrm{Ba}^{2+}$ as the charge carrier to minimize interference from any $\mathrm{Ca}^{2+}$-activated currents. Figure 1 illustrates experiments performed to examine possible effects of 

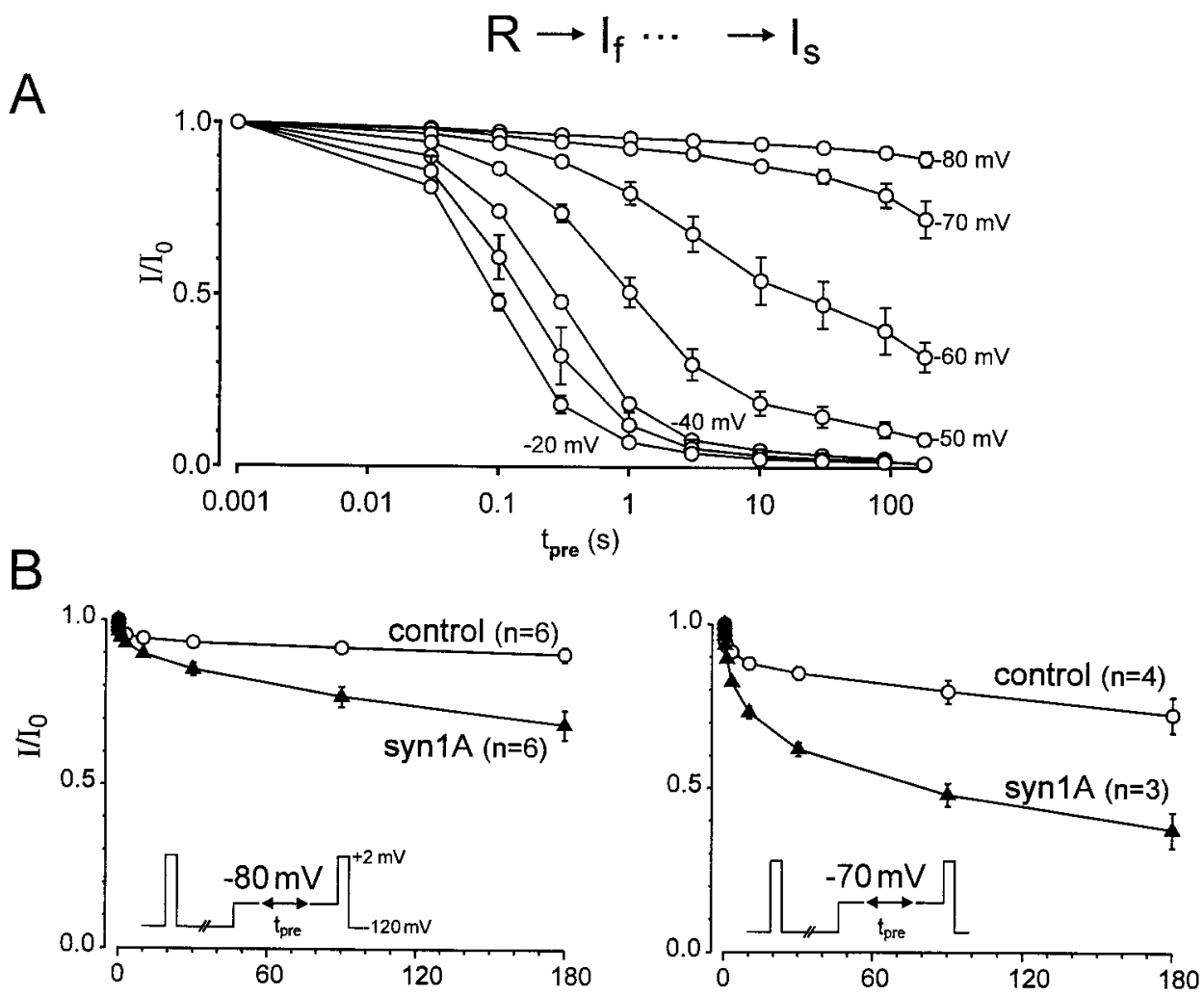

Figure 2. $I_{\mathrm{Ba}}$ inactivation and effect of syntaxin on a slow time scale. $A$, Inactivation of $I_{\mathrm{Ba}}$ at different prepulse potentials, studied with the same protocol as in Figure $1 B$. Control data in panel $B$, plotted on a logarithmic time scale. $B$, Influence of syntaxin on slow inactivation. Each panel shows the development of $I_{\mathrm{Ba}}$ inactivation at a specific conditioning potential, as indicated in the insets. Data in the absence of syn1A (open circles) and with syn1A present (filled triangles). Conditioning prepulses of progressively increasing duration $\left(t_{\text {pre }}\right)$ were applied from $V_{\mathrm{h}}=-120 \mathrm{mV}$, with test pulses $(+2 \mathrm{mV}, 20 \mathrm{msec})$ applied before and immediately after the prepulse. The membrane was held for $1 \mathrm{~min}$ at $-120 \mathrm{mV}$ before obtaining each data point. After a series of measurements with a given prepulse potential, $V_{\mathrm{h}}$ was held at $-120 \mathrm{mV}$ for $8-10$ min before starting a new series with a different prepulse potential $10 \mathrm{mV}$ more depolarized than the previous one. The $I_{\mathrm{Ba}}$ evoked after the prolonged hyperpolarization, without any prepulse (amplitude $I_{0}$ ) was used for normalization $\left(I / I_{0}\right)$. This procedure highlights the combination of fast and slow inactivation $\left(R \rightarrow I_{\mathrm{f}}, R \rightarrow I_{\mathrm{f}} \ldots \rightarrow I_{\mathrm{s}}\right)$.

syntaxin on rapid inactivation. Properties of rapid inactivation were characterized over the range between -80 and $+40 \mathrm{mV}$ by use of two approaches. At potentials beyond the level where significant $I_{\mathrm{Ba}}$ activation became evident, near $-20 \mathrm{mV}$ under our experimental conditions, fast inactivation was measured as the rate of $I_{\mathrm{Ba}}$ decay. The decay rate was assessed over a fixed interval 30-100 msec after the depolarizing step to avoid interference from changes in the degree of activation (Fig. 1A). At more negative potentials, at or below threshold for significant $I_{\mathrm{Ba}}$ activation, the onset of fast inactivation was studied by imposing prepulses of various durations followed by a fixed test pulse to elicit $I_{\mathrm{Ba}}($ Fig. $1 B)$. In both protocols, the membrane was held at a strongly negative potential between successive trials to ensure complete recovery from inactivation before each measurement. The rate of inactivation increased steeply as the level of depolarization increased, reaching a peak at $-10 \mathrm{mV}$, before falling off with even stronger depolarizations up to $+40 \mathrm{mV}$ (Fig. 1C). The voltage dependence is typical of that previously reported for N-type channels in neurons (Kasai and Aosaki, 1988; Jones and Marks, 1989; Cox and Dunlap, 1994).

Coexpression of syntaxin 1A (syn1A) with the N-type channels did not produce a significant change in their rapid gating kinetics (Fig. 1C). Recordings on a millisecond time scale (data not shown) revealed no significant difference in activation kinetics in oocytes expressing syntaxin 1A comparing to control cells. Rapid inactivation was also unaffected by coexpression of syntaxin $1 \mathrm{~A}$, monitored as the initial rate of $I_{\mathrm{Ba}}$ decay or studied with subthreshold depolarizing prepulses. Irrespective of the presence or absence of exogenous syntaxin, the rate of inactivation reached a maximum of $\sim 8 \mathrm{sec}^{-1}$ at $-10 \mathrm{mV}$ and decreased at higher potentials.

\section{Effect of syntaxin on development of slow inactivation}

Clear effects of syntaxin emerged when we studied slow inactivation of $\mathrm{N}$-type $\mathrm{Ca}^{2+}$ channels during prolonged depolarizations, using the same protocol as in Figure $1 B$ but with prepulses extended to a time scale of seconds or min (Fig. 2). Inactivation of $I_{\mathrm{Ba}}$ was assessed as a decrease in the ratio of current amplitudes in the presence and absence of the depolarizing prepulse ( $I$ and $I_{0}$, respectively). Inactivation of $I_{\mathrm{Ba}}$ in control oocytes proceeded with multiple phases as illustrated by a plot of $I / I_{0}$ against log time (Fig. 2A). At various prepulse potentials, significant kinetic 
changes were observed over time ranges of a hundred milliseconds, several seconds, and minutes, typical of N-type channels in neurons (Jones and Marks, 1989). The slowly developing inactivation was hardly detectable at $-80 \mathrm{mV}$ but was quite obvious at -70 and $-60 \mathrm{mV}$. Even on a log scale, the progressive decrease in test current would be difficult to separate into clearly defined exponential components with well separated time constants, in part because the decay had not achieved steady-state at $300 \mathrm{sec}$. Coexpression of syntaxin strongly accentuated the effect of moderate depolarizations, greatly increasing their ability to attenuate $I_{\mathrm{Ba}}$ (Fig. $2 B$ ). Slow inactivation could now be readily detected at $-80 \mathrm{mV}$ and became much more prominent at -70 and $-60 \mathrm{mV}$. Syn1A did not promote $I_{\mathrm{Ba}}$ decay at potentials levels of $-40 \mathrm{mV}$ and higher (see Fig. 2, panel $-20 \mathrm{mV}$ ). Instead, in oocytes expressing syntaxin, there was an increase in the prominence of inactivation over a range of a few seconds, so that completion of the last phase of $I_{\mathrm{Ba}}$ inactivation took longer than in control. We did not attempt to analyze this phenomenon in detail, but this would be a worthwhile topic for future study.

\section{Influence of syntaxin on recovery from inactivation}

We found that the differential effects of syntaxin on fast and slow aspects of the inactivation extended to recovery from inactivation as well as its onset. Figure 3 illustrates a test of whether syntaxin affects recovery from fast inactivation, assessed by a classic twopulse procedure. After a $1 \mathrm{sec}$ conditioning pulse to inactivate $I_{\mathrm{Ba}}$, recovery from inactivation was assessed by application of a test pulse at a variable interval. The rate of recovery of test current amplitude was strongly dependent on the membrane potential at which the recovery occurred $(-120$ or $-80 \mathrm{mV}$; Fig. $3 A)$, in accord with voltage-dependent recovery from inactivation in other systems. However, at any given potential, coexpression of syntaxin (Fig. $3 B$ ) did not significantly affect the time course of recovery relative to control (Fig. $3 A$ ). Results from similar experiments were pooled to describe recovery from inactivation over a wide range of potentials (Fig. $3 C$ ). Little or no difference in the initial recovery rate was found between control and syn1Aexpressing oocytes at any potential between -40 and $-120 \mathrm{mV}$ (Fig. 3D).

We found a very different pattern of behavior in the recovery from slow inactivation produced by a prolonged depolarization, illustrated in Figure 4. The records on the left show behavior at a holding potential of $-120 \mathrm{mV}$. In the absence of coexpressed syntaxin, double pulse experiments showed a slow restitution of $I_{\mathrm{Ba}}$ that reached half-maximum at an interval roughly $4 \mathrm{sec}$ after the repolarizing step. The expression of syntaxin produced an additional stabilization of slow inactivation, so that $I_{\mathrm{Ba}}$ now required $>30 \mathrm{sec}$ to achieve $50 \%$ recovery (Fig. $4 B$ ). This more than sevenfold slowing of the half-time of recovery was corroborated in pooled results from three oocytes (Fig. 4C). Even more striking effects were seen at a holding potential of $-80 \mathrm{mV}$ (Figs. $4 A, B$ right, 5). The half-time for recovery was $0.5-1 \mathrm{~min}$ in control experiments, but in the presence of syntaxin, $50 \%$ restitution was still not achieved even at 6 min (Fig. 4C, right).

The wide variation in recovery kinetics is seen most clearly in Figure 5, $A$ and $B$, which plots time on a log scale to encompass recovery intervals ranging from $10^{-2}$ to $>10^{2} \mathrm{sec}$. Data for the 1 sec and 6 min depolarizations are summarized, together with results obtained with a $30 \mathrm{sec}$ depolarization. After the $1 \mathrm{sec}$ depolarization (open circles), the fastest component of repriming (rate, $\sim 8 \mathrm{sec}^{-1}$ ) clearly dominates (for comparison, a single exponential time course is indicated by the dotted curve). How-
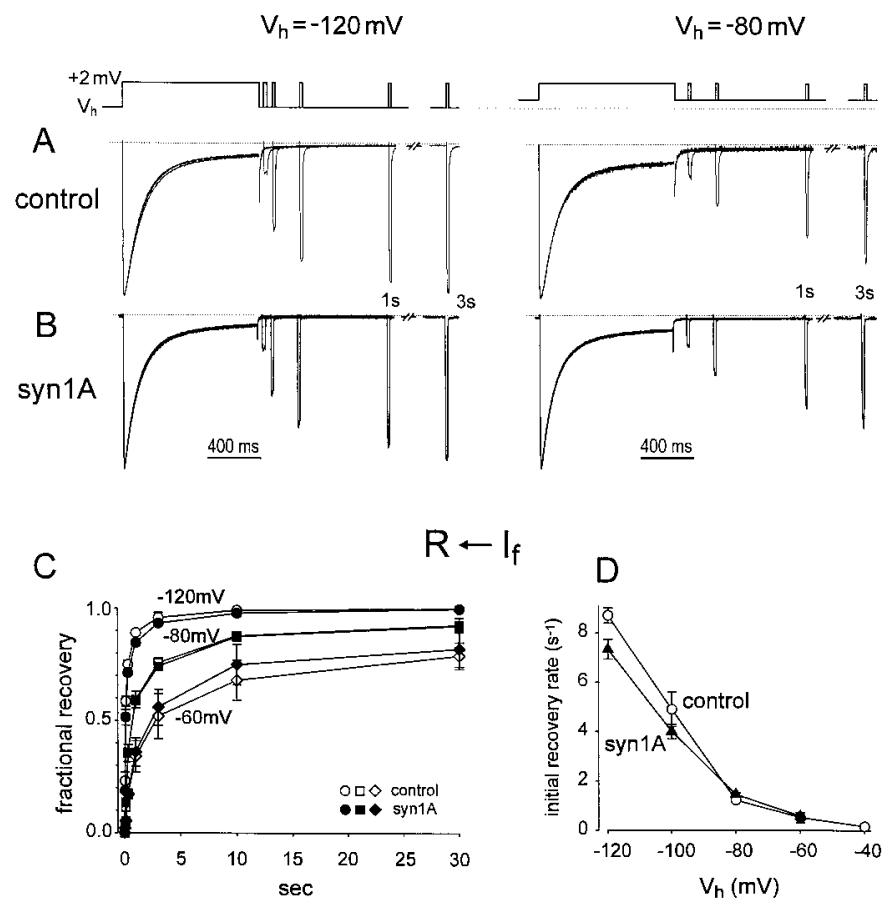

Figure 3. Effect of syntaxin on recovery of $I_{\mathrm{Ba}}$ from fast inactivation. $A$, $B$, Recovery of $I_{\mathrm{Ba}}$ from inactivation in the absence $(A)$ and presence of syntaxin $(B)$. Inactivation was evoked by $1 \mathrm{sec}$ voltage pulses from $V_{\mathrm{h}}=$ $-120 \mathrm{mV}$ to $+2 \mathrm{mV}$ (left panels) or from $V_{\mathrm{h}}=-80 \mathrm{mV}$ to $+2 \mathrm{mV}$ (right panels). Recovery from inactivation was assayed with single $15 \mathrm{msec}$ test pulses, applied after various time intervals after the $1 \mathrm{sec}$ pulse (voltage protocol shown above). Between successive measurements, $V_{\mathrm{h}}$ was held at $-120 \mathrm{mV}$ for $1 \mathrm{~min}$ to achieve recovery from inactivation. For recovery at $-80 \mathrm{mV}$ (right panels), membrane potential was held at $-120 \mathrm{mV}$ for 30 sec followed by 2 min at $-80 \mathrm{mV}$, before evoking $I_{\mathrm{Ba}}$. All recordings of $I_{\mathrm{Ba}}$ were normalized to peak amplitude during the conditioning pulse. $C$, Time courses of $I_{\mathrm{Ba}}$ recovery at -120 (circles), -80 (squares), and $-60 \mathrm{mV}$ (diamonds) in control (open symbols; $n=3$ ) and with syn1A (filled symbols; $n=3-4)$. "Fractional recovery" from inactivation was defined as the portion of inactivated current which recovered at a given time relative to the maximal possible recovery. Thus fractional recovery $=$ $\left(I_{\mathrm{t}}-I_{1 \mathrm{sec}}\right) /\left(I_{\infty}-I_{1 \mathrm{sec}}\right)$, where $I_{\mathrm{t}}$ refers to peak current evoked at time $t$ after repolarization, $I_{1 \mathrm{sec}}$ represents the current level at the end of the $1 \mathrm{sec}$ pulse, and $I_{\infty}$ was the fully recovered current, taken as the peak current evoked by the $1 \mathrm{sec}$ pulse itself. $R \leftarrow I_{\mathrm{f}}$ denotes recovery from fast inactivation. $D$, Voltage dependence of initial rate of recovery from inactivation. The initial rate was determined from the recovery of $I_{\mathrm{Ba}}$ over the first $100 \mathrm{msec}$ after repolarization, assuming an exponential process during this initial period (fractional recovery $(t)=1-\exp \left[-\mathrm{k}_{\text {recov }}{ }^{*} t\right]$ ). Voltage protocol for recovery at $V_{\mathrm{h}}=-60 \mathrm{mV}$ and other levels was similar to that for $V_{\mathrm{h}}=-80 \mathrm{mV}(A, B$, right panels $)$.

ever, this aspect of recovery had virtually disappeared after a 30 sec depolarization (open triangles). After the $30 \mathrm{sec}$ depolarization, syntaxin produced a significant delay in repriming ( filled triangles). A dramatic effect of syn1A on repriming kinetics was observed in the wake of the 6 min depolarization (compare open and filled squares).

\section{Interconversion between syntaxin-insensitive and syntaxin-sensitive aspects of inactivation}

The results presented so far established that syntaxin accentuated slow inactivation of $\mathrm{N}$-type $\mathrm{Ca}^{2+}$ channels but spared fast inactivation. Slow inactivation was a prominent feature of $\alpha_{1 \mathrm{~B}}$ subunits expressed in the Xenopus oocyte expression system (Bezprozvanny et al., 1995; Stocker et al., 1997), very similar to the behavior of the corresponding $\mathrm{N}$-type $\mathrm{Ca}^{2+}$ channels in neurons 

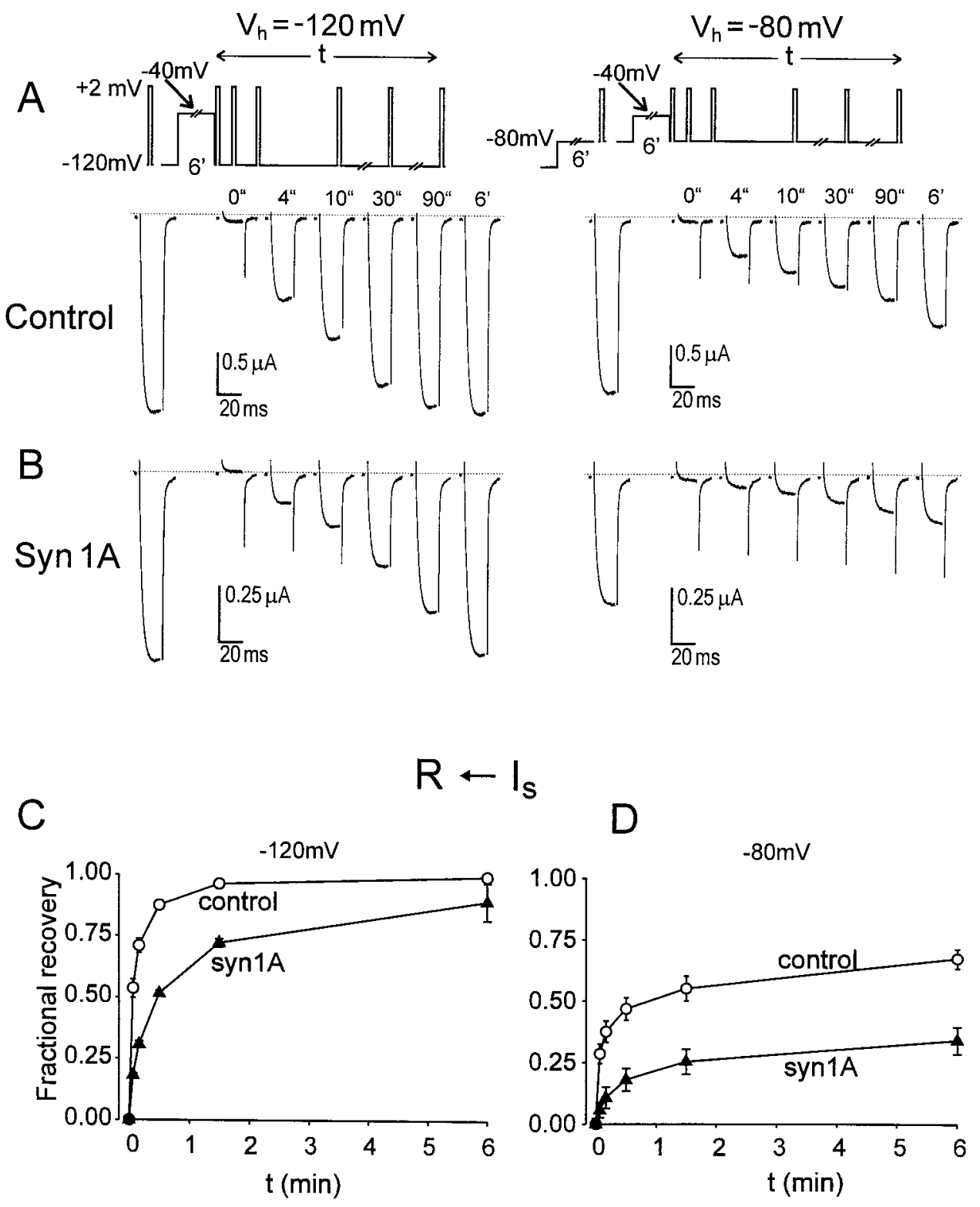

Figure 4. Effect of syntaxin on recovery of $I_{\mathrm{Ba}}$ from slow inactivation. $A, B$, Recovery from slow inactivation produced by a previous $6 \mathrm{~min}$ prepulse to $-40 \mathrm{mV}$. Recovery of $I_{\mathrm{Ba}}$ was measured with a series of $20 \mathrm{msec}$ test pulses to $+2 \mathrm{mV}$, applied one after each other at indicated times after repolarization to either $-120 \mathrm{mV}$ (left) or $-80 \mathrm{mV}$ (right). Before applying the prepulse, $V_{\mathrm{h}}$ was held at $-120 \mathrm{mV}$ for $>6 \mathrm{~min}$ for complete recovery from inactivation (left panels). In experiments shown in the right panels, $V_{\mathrm{h}}$ was first held for $5 \mathrm{~min}$ at $-120 \mathrm{mV}$, then stepped to $-80 \mathrm{mV}$ for the following 6 min to produce a quasi-steadystate. $I_{\mathrm{Ba}}$ amplitude was measured with $V_{\mathrm{h}}=-80 \mathrm{mV}$ before the prepulse. $C, D$, Time courses of $I_{\mathrm{Ba}}$ recovery at -120 and $-80 \mathrm{mV}$ in control (open circles; $n=3$ ) and in the presence of syn1A ( filled triangles; $n=3-4)$. Fractional recovery was determined as $\left(I_{\mathrm{t}}-I_{-40}\right) /\left(I_{\infty}-I_{-40}\right)$, where $\mathrm{I}_{\mathrm{t}}$ is the current amplitude evoked at time $t$ after the depolarization, $I_{-40}$ refers to current taken immediately after 6 min prepulse to $-40 \mathrm{mV}$ (corresponds to $\mathrm{t}=0$ ), and $I_{\infty}$ stands for $I_{\mathrm{Ba}}$ evoked before the $-40 \mathrm{mV}$ prepulse, after membrane had been held for $6 \mathrm{~min}$ at either $-120(C)$ or $-80 \mathrm{mV}(D)$.

(Jones and Marks, 1989). Slow inactivation could be readily distinguished from fast inactivation by large differences in speed of onset and recovery (tens of seconds or minutes rather than hundreds of milliseconds; it was most prominent at relatively negative potentials where little or no fast inactivation took place. These features were reminiscent of sodium channel gating in a variety of excitable tissues (see Discussion). Although studies of fast and slow inactivation in $\mathrm{Na}^{+}$channels are very extensive, no consensus has yet emerged about the topological relationship between the kinetic states that underlie these processes. Likewise, our results do not permit us to derive an explicit kinetic model, although they provide useful clues as to how fast and slow inactivation might be related to each other (see below). We focused on achieving an operational separation of these processes, using various voltage protocols that removed fast inactivation while largely preserving slow inactivation.

Further experiments were undertaken to determine the speed of conversion between rapid, syntaxin-insensitive recovery kinetics and slow, syntaxin-sensitive repriming (Fig. 5C,D). The de- gree of inactivation was studied with a standardized voltage protocol that focused on slow inactivation (Fig. 5C, inset) (Bezprozvanny et al., 1995). After a variable period of conditioning depolarization ( $V_{\text {pre }}$; Fig. $5 C$, inset), the membrane potential was shifted to $-80 \mathrm{mV}$ for $100 \mathrm{sec}$ to allow channels to recover from faster components of inactivation. The repetitive application of test pulses provided continuous monitoring of kinetic changes at each holding potential. The amplitude of the last test current evoked by a test pulse from $-80 \mathrm{mV}\left(I_{80}\right)$ was referred to the last test current evoked after further hyperpolarization to $-120 \mathrm{mV}$ for $200 \mathrm{sec}\left(I_{120}\right)$. The ratio of current amplitudes $\left(I_{80} / I_{120}\right)$ reflected the degree of channel availability left by the slow inactivation during the conditioning depolarization (Fig. 5C). The suitability of this index can be judged by the kinetic data in Figure $5, A$ and $B$. The $100 \mathrm{sec}$ sojourn at $-80 \mathrm{mV}$ was ample to allow complete recovery from fast inactivation (Fig. $5 B$, recovery after 1 sec pulses), but short enough to forestall recovery of a substantial fraction of slowly inactivated channels even in the absence of syntaxin (Fig. $5 B$, recovery after 6 min pulses in control oocytes). 
Figure 5. Kinetics of syntaxin stabilization of slowed recovery from inactivation. $A, B$, Comparison of time courses of $I_{\mathrm{Ba}}$ recovery from inactivation in the wake of depolarizing prepulses of various durations, $1 \mathrm{sec}$ (circles), $30 \mathrm{sec}$ (triangles), and $6 \mathrm{~min}$ (squares), in control (open symbols) and with syn1A ( filled symbols). $V_{\mathrm{h}}=-120(A)$, and $V_{\mathrm{h}}=$ $-80 \mathrm{mV}(B)$. Protocols for recovery after 1 sec and 6-min-long depolarization are described in the legends to Figures 3 and 4. Protocol for restitution after $30 \mathrm{sec}$ conditioning pulse was like that described for 6 min prepulses. Between successive measurements, the membrane potential was held at $-120 \mathrm{mV}$ for $1 \mathrm{~min}(A)$ or for $10 \mathrm{sec}$ at -120 $\mathrm{mV}$ followed by $2 \mathrm{~min}$ at $-80 \mathrm{mV}(B)$. Thin dotted line is a single exponential curve, fitted to the initial recovery from fast inactivation. $\left(R \leftarrow I_{\mathrm{f}}\right) \rightarrow\left(R \leftarrow I_{\mathrm{s}}\right)$ scheme on top denotes transition between processes of recovery from fast inactivation (for recovery after 1 sec pulses) and from slow inactivation (for 30 sec and 6 min prepulses). $C$, Time course of development of slowed recovery from inactivation. Influence of a depolarizing prepulse was assessed by descending staircase protocol (inset). Degree of slow inactivation was gauged by recovery of $I_{\mathrm{Ba}}$ at $-80 \mathrm{mV}$ relative to recovery at $-120 \mathrm{mV}\left(I_{80} / I_{120}\right.$ ratio; Bezprozvanny et al., 1995). After strong hyperpolarization $(-120 \mathrm{mV}, 7-8 \mathrm{~min})$, the membrane was held depolarized at a prepulse level of $-40 \mathrm{mV}$ for a variable time $\left(t_{\mathrm{pre}}\right) \cdot I_{\mathrm{Ba}}$ was evoked by $20 \mathrm{msec}$ test pulses to $+2 \mathrm{mV}$ at $0.1 \mathrm{~Hz}, 10$ pulses from $V_{\mathrm{h}}=-80 \mathrm{mV}$, then 20 pulses from $-120 \mathrm{mV}$. Data were fit with the function $\mathrm{A}^{*} \exp (-t / \tau)+C$, using the following parameter values for control or syn1A respectively: $\tau, 5.1$ or $3.1 \mathrm{~min} ; A, 0.6$ or $0.58 ; C, 0.29$ or 0.3 . $D$, Voltage dependence of syn1A effect assessed by reduction of $I_{80} /$ $I_{120}$ at various prepulse levels. Voltage protocol as in $C$. The initial rate of development of slow inactivation was estimated from the decline in $I_{80} / I_{120}$ after a 2 min depolarization at the $V_{\text {pre levels shown, assuming an }}$ exponential time course over that period.
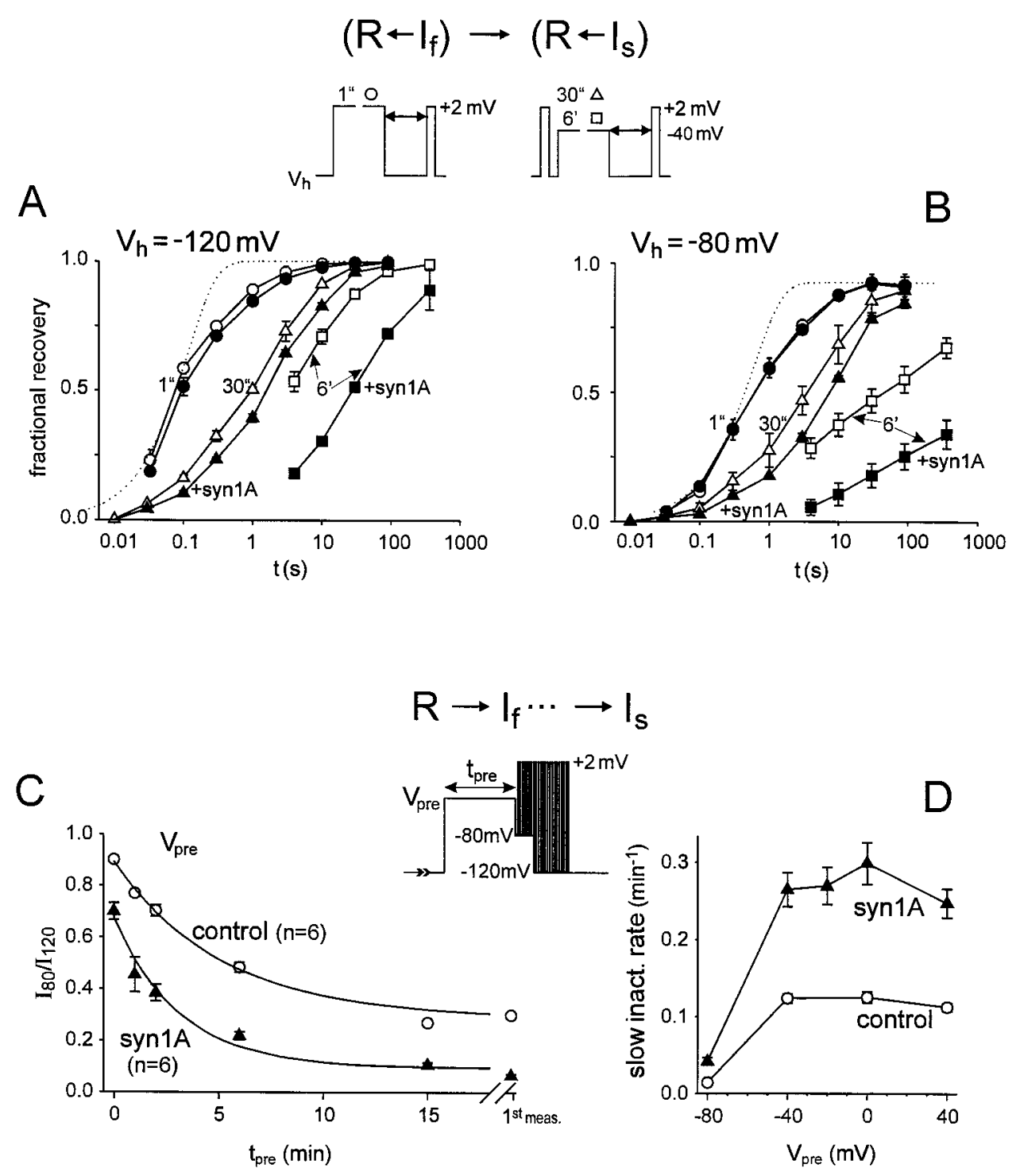

The subsequent $200 \mathrm{sec}$ period at $-120 \mathrm{mV}$ allowed nearly complete recovery from slow inactivation after 6 min pulses, even in the presence of syntaxin (Fig. 5A). Thus, the impact of residual slow inactivation on channel availability was assessed in a relatively efficient manner.

As illustrated in Figure $5 C$ for a conditioning depolarization to $-40 \mathrm{mV}$, the $I_{80} / I_{120}$ ratio declined exponentially as the duration of the conditioning pulse $\left(t_{\text {pre }}\right)$ was progressively increased. The degree of stabilization of slow inactivation was increased by syntaxin, as indicated by a sharp reduction in $I_{80} / I_{120}$ after long prepulses. The rate of decay $\left(\tau^{-1}\right)$ also increased, from $\sim 0.12$ $\min ^{-1}$ in control to $\sim 0.27 \mathrm{~min}^{-1}$ in syntaxin. The voltage dependence of $\tau^{-1}$ was analyzed by varying $V_{\text {pre }}($ Fig. $5 D)$. The rate of entry into the stabilized inactivated state was sensitive to membrane potentials between -80 and $-40 \mathrm{mV}$, but not at more depolarized potentials up to $+40 \mathrm{mV}$. This was true in both the presence and absence of syntaxin.

\section{Detection of the effect of syntaxin on inactivation depends critically on voltage protocol}

These observations have bearing on the interpretation of experiments testing whether syntaxin is capable of modifying the availability of N-type channels. Figure 6 compares the results obtained with four different voltage protocols for assessing the voltage dependence of $I_{\mathrm{Ba}}$ inactivation. The protocol in panel $A$ uses $3 \mathrm{sec}$ depolarizing prepulses, applied from a relatively negative holding potential $\left(V_{\mathrm{h}}\right)$, representative of most studies to date (prepulse durations $2 \mathrm{sec}$ ) (Mochida et al., 1996; Wiser et al., 1996; Stanley and Mirotznik, 1997). In this case the influence of syntaxin was barely detectable. However, there was a clear cut difference in availability measured with 3 min prepulses in the same set of oocytes (Fig. 6B), consistent with the action of syntaxin on slow rather than fast inactivation.

Another perspective on the impact of syntaxin on slow changes in N-type channel availability is illustrated by comparison of panels $C$ and $D$ in Figure 6. Inactivation curves were derived by measuring $I_{\mathrm{Ba}}$ after 30 -sec-long prepulses in the same set of oocytes, the only differences residing in the holding potential, and the direction in which the prepulse level was varied. Figure $6 C$ shows results obtained with an ascending series of prepulses $(-100 \mathrm{mV}$ up to $-20 \mathrm{mV})$, applied from $V_{\mathrm{h}}=-120 \mathrm{mV}$. In this case, the effect of syntaxin expression was relatively mild $\left(V_{1 / 2}\right.$ values of -60 in control and $-66 \mathrm{mV}$ with syntaxin), but never- 
A
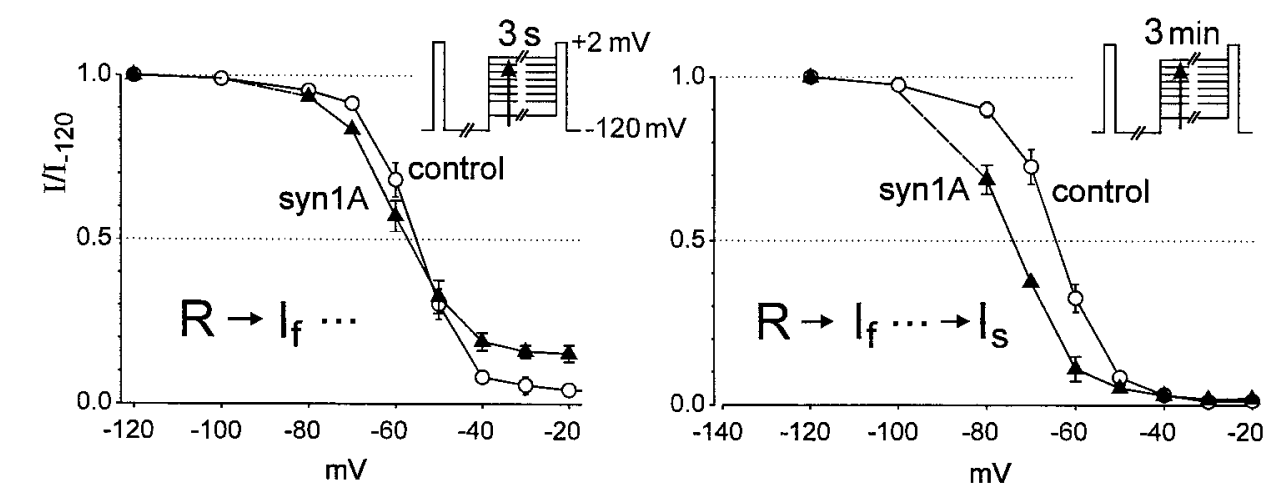

Figure 6. Apparent effect of syntaxin on availability of $\mathrm{Ca}^{2+}$ channels depends critically on voltage protocol. $A, B$, Isochronal availability curves, measured in the same oocytes with $3 \mathrm{sec}(A)$ or $3 \mathrm{~min}(B)$ depolarizing prepulses applied from $V_{\mathrm{h}}=-120$ $\mathrm{mV}$. Points derived from inactivation curves $(n=3-7)$ like those shown in Figure 2. $C$, Availability of $I_{\mathrm{Ba}}$ derived with $30 \mathrm{sec}$ prepulses applied from $V_{\mathrm{h}}=-120 \mathrm{mV}$ in ascending order (from $-100 \mathrm{mV}$ up to -20 $\mathrm{mV}$ ). Control, $n=5$; syn1A, $n=4$. After each measurement of $I_{\mathrm{Ba}}, V_{\mathrm{h}}$ was returned to $-120 \mathrm{mV}$ for $30 \mathrm{sec}$ to restrict any influence of previously developed inactivation. Peak $I_{\mathrm{Ba}}$ amplitudes were normalized by that measured after complete recovery from inactivation at $-120 \mathrm{mV}$. $D$, Avail-
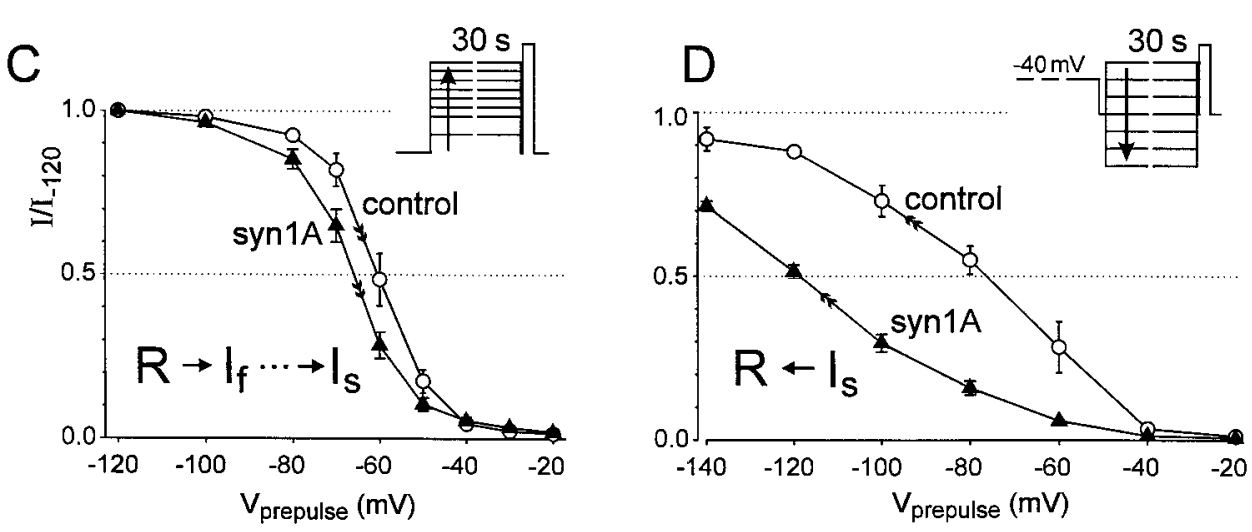
ability of $I_{\mathrm{Ba}}$, derived with a series of descending voltage steps between -20 and $-140 \mathrm{mV}$, each lasting $30 \mathrm{sec}$. Control, $n=$ 5 ; syn1A, $n=4$. The oocyte membrane was held for $6 \mathrm{~min}$ at $-40 \mathrm{mV}$ to allow slow inactivation to develop before the descending series of prepulses. Membrane potential stepped for $20 \mathrm{msec}$ to $-80 \mathrm{mV}$ before test pulses $(+2 \mathrm{mV}, 50 \mathrm{msec})$, then stepped to the following prepulse potential. In the presence of syntaxin, $I_{\mathrm{Ba}}$ did not recover completely from inactivation even after the last prepulse (to $-140 \mathrm{mV}$ ). Current amplitudes were therefore normalized by the maximal value used in $C$, measured in the same oocyte after complete recovery from inactivation had been achieved at $-120 \mathrm{mV}$.

theless significant. These data may be compared with the response of the same set of cells to a descending series of prepulses (between -20 and $-140 \mathrm{mV}$ ) after the membrane potential had been held for $3 \mathrm{~min}$ at $V_{\mathrm{h}}=-40 \mathrm{mV}$ (Fig. $6 D$ ). $I_{\mathrm{Ba}}$ amplitudes were normalized by the one measured at $-120 \mathrm{mV}$ after complete recovery from inactivation after prolonged repolarization. Here the voltage dependence of availability was strikingly different in control and syn1A-expressing oocytes, with midpoint voltages separated by $\sim 45 \mathrm{mV}\left(V_{1 / 2}=-74 \mathrm{mV}\right.$ in control and $-120 \mathrm{mV}$ in syntaxin). The disparity between the voltage displacements- 6 $\mathrm{mV}$ in panel $C$ and $45 \mathrm{mV}$ in panel $D$-underscores the difficulty of achieving "steady-state" inactivation in a system that requires several minutes or longer to come into equilibrium. The impact of slow inactivation is evident even under control conditions. In the absence of syntaxin, ascending and descending protocols yield quite different values for midpoint voltages and slopes for inactivation curves (Fig. 6C,D). Even with $30 \mathrm{sec}$ prepulses, the previous history of membrane potential had a very strong impact on the measurements of availability. The discrepancy in midpoint voltages in control $(14 \mathrm{mV})$ gave a significant "hysteresis" that was greatly magnified by the presence of syntaxin $(54 \mathrm{mV})$.

\section{Trains of action potential-like pulses promote the effect of syntaxin on slow inactivation}

The preceding experiments demonstrated that the impact of syntaxin on channel gating was strongly influenced by changes in membrane potential over the range of normal resting potentials, over a time scale of minutes. In addition to continuous depolarizations, we also tested the effects of trains of brief depolarizing pulses, possibly relevant to the impact of syntaxin during repeti- tive action potential firing in nerve terminals (Bergsman and Tsien, 2000). We observed fast inactivation that developed with a delay after single depolarizing pulses lasting a few milliseconds, termed "hidden inactivation" by Patil et al. (1998). Coexpression of syntaxin had no detectable influence on the time course or degree of hidden inactivation (data not shown). There was also no significant effect of syntaxin on the progressive decline in peak $\mathrm{Ca}^{2+}$ channel current during trains of depolarizing pulses lasting tens of seconds (Fig. 7A). Both of these observations were in concordance with our analysis of the effects of syntaxin on rapid $\mathrm{Ca}^{2+}$ channel inactivation, studied with conventional depolarizing pulses (Fig. 1). A different picture emerged for the slow inactivation arising from trains of brief depolarizations (Fig. 7B). Experimental protocols were chosen to focus specifically on slowly recovering inactivation resulting from repetitive pulsing (e.g., 2 msec pulses to $+10 \mathrm{mV}$ every $10 \mathrm{msec}$; Fig. $7 B$ ). After pulse trains of various overall durations, the residuum of slow inactivation was assessed by determination of the $I_{80} / I_{120}$ ratio, just as in the earlier experiments with steady depolarizations (Fig. 6 ). We found that trains of brief pulses were significantly more effective in causing this ratio to decay than steady depolarizations to the same level (Fig. $7 B$ ). This result was particularly striking because it was the overall train duration that was plotted, not the cumulative time spent at the depolarized level. It was surprising, but clear, that pulse trains were more efficient than steady depolarization in producing slow inactivation.

Figure $7 C$ shows the effect of coexpressing syntaxin on the $I_{80} / I_{120}$ ratio and its dependence on pulse train duration. As the pulse train was extended, the ratio fell to $\sim 0.5$ within $2 \mathrm{~min}$ in 


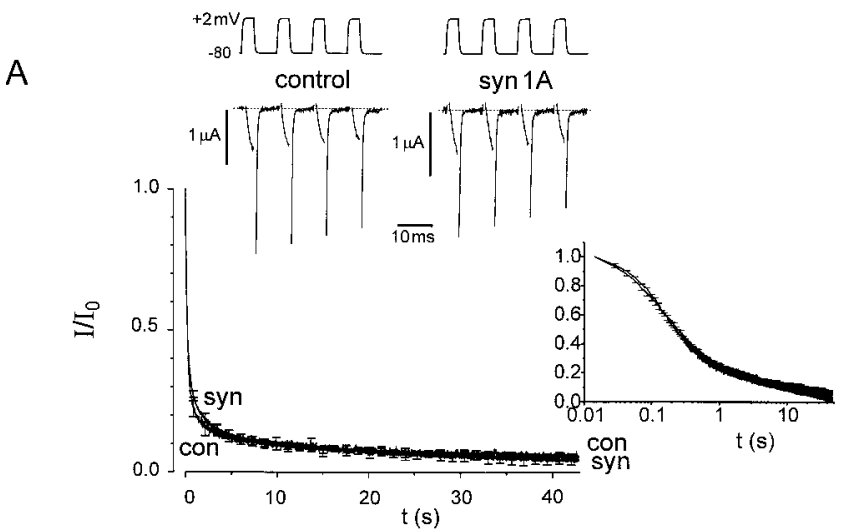

B
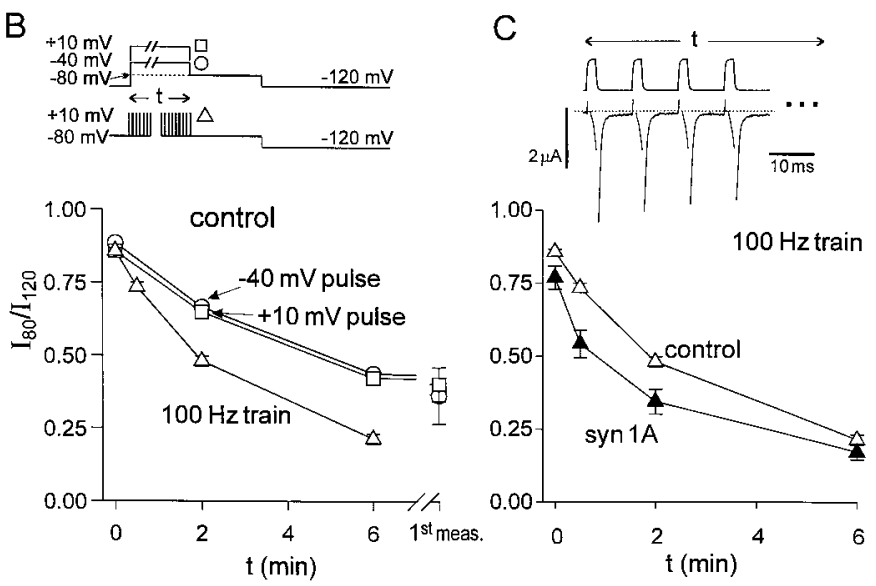

Figure 7. Effect of syntaxin on fast and slow inactivation during trains of brief pulses or continuous depolarizations. $A$, Time courses of $I_{\mathrm{Ba}}$ inactivation produced by stimulation with repetitive pulses in the absence (con) and presence of syntaxin (syn). $I_{\mathrm{Ba}}$ was elicited by $70 \mathrm{~Hz}$ trains of 5 msec depolarizing pulses from $V_{\mathrm{h}}=-80$ to $+2 \mathrm{mV}$. Inset, Same data, plotted on a logarithmic time scale to highlight early changes. Top, Representative records in the presence and absence of syn1A, taken at the beginning of the stimulus train. $B$, Comparison between trains of pulses and continuous depolarization with regard to stabilization of slow inactivation. $I_{80} / I_{120}$ ratio measured after conditioning stimulation of variable duration (voltage protocols shown above; see Fig. 5C, legend for details). Pulses to $-40 \mathrm{mV}$ (circles), $+10 \mathrm{mV}$ (squares), or $100 \mathrm{~Hz}$ trains of $2 \mathrm{msec}$ pulses from $V_{\mathrm{h}}=-80$ to $+10 \mathrm{mV}$ (triangles). $C$, Slow inactivation produced by trains of pulses in the absence (open triangles) and presence of syn1A ( filled triangles). Exemplar membrane potential and current recordings are shown above.

the absence of syn1A, but required only $\sim 30 \mathrm{sec}$ to undergo the same decay in its presence. By this reckoning, syntaxin caused a nearly fourfold acceleration of the kinetics of slow inactivation.

\section{Temperature dependence of syntaxin action}

All of the experiments presented so far were performed at room temperature $\left(23^{\circ} \mathrm{C}\right)$ to facilitate long-lasting recordings from the Xenopus oocytes. However, it was of considerable interest to find out whether syntaxin effects on $\mathrm{Ca}^{2+}$ channel gating could also be observed at warmer temperatures more relevant to mammalian physiology. We observed a dramatic acceleration of activation and fast inactivation kinetics at $35^{\circ} \mathrm{C}$ relative to $25^{\circ} \mathrm{C}$ (Fig. $8 \mathrm{~A}$ ). For example, at $+10 \mathrm{mV}$, a potential level studied with both prolonged voltage steps and trains of pulses, the rate of rapid inactivation was increased with warming from $5.0 \pm 1.2 \mathrm{sec}^{-1}$ to $21.8 \pm 2.5 \mathrm{sec}^{-1}$ (Fig. $8 B$ ). The speeding of fast inactivation was in accord with previous results for other voltage-gated ion chan-
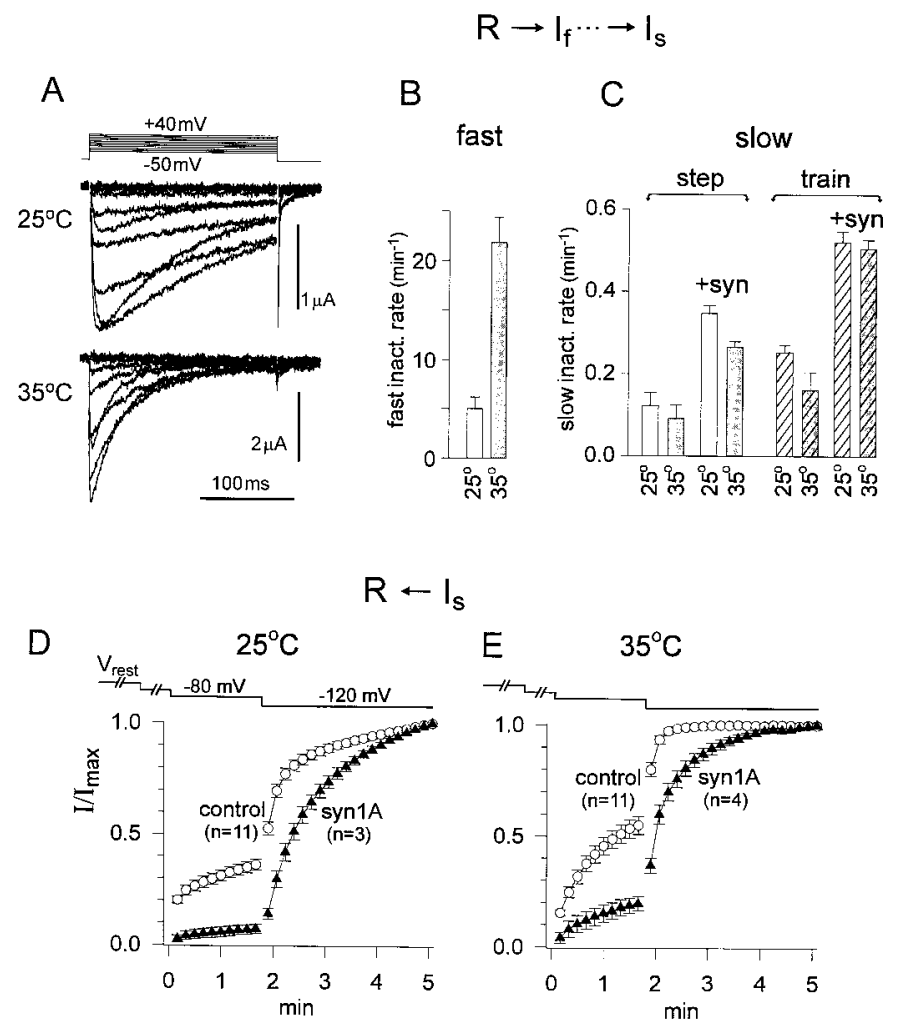

Figure 8. Temperature dependence of fast and slow inactivation and the influence of syntaxin. $A$, Family of $I_{\mathrm{Ba}}$ traces elicited by $200 \mathrm{msec}$ test pulses to levels between -50 and $+40 \mathrm{mV}$, taken at $25^{\circ} \mathrm{C}$ and $35^{\circ} \mathrm{C}$ with no coexpressed syn $1 \mathrm{~A}$. Leak current was subtracted with $\mathrm{P} / 4$ algorithm. $B$, Initial rate of $I_{\mathrm{Ba}}$ decay during test pulse $+10 \mathrm{mV}$ at $25^{\circ} \mathrm{C}(n=3)$ or $35^{\circ} \mathrm{C}$ $(n=3)$. $C$, The initial rate of slow inactivation, gauged by decline of $I_{80} / I_{120}$ during the initial 2 min of stimulation (Figs. $5 D, 7 B$ ). Comparison of results at $25^{\circ} \mathrm{C}$ (open bars) or $35^{\circ} \mathrm{C}$ ( gray bars), in the absence (con) and presence of syn1A (syn). Stimuli were continuous voltage depolarizations ("step", unhatched bars) or repetitive pulses ("train", hatched bars) $(n=3$ oocytes for each condition). $D, E$, Time course of $I_{\mathrm{Ba}}$ recovery from slow inactivation, produced by progressive hyperpolarization (voltage protocol shown above). Recordings taken in the absence and presence of syn1A at $25^{\circ} \mathrm{C}(D)$ and $35^{\circ} \mathrm{C}(E)$. Slow inactivation had developed at the resting potential (typically -25 to $-15 \mathrm{mV}$ ) before the oocyte membrane was voltage-clamped.

nels. On the other hand, the same increase in temperature failed to accelerate the development of slow inactivation under any experimental conditions tested, regardless of whether inactivation was produced by continuous depolarization or pulse trains and whether or not syntaxin was coexpressed (Fig. $8 \mathrm{C}$ ). At $35^{\circ} \mathrm{C}$, just as at $25^{\circ} \mathrm{C}$, slow inactivation was favored by the presence of syntaxin, and repetitive application of brief pulses was more effective than a continuous depolarization.

Recovery from slow inactivation was strongly affected by warming from $25^{\circ} \mathrm{C}$ to $35^{\circ} \mathrm{C}$ (Fig. $8 D, E$ ). This was studied by applying incremental hyperpolarizations, first to $-80 \mathrm{mV}$ and then to $-120 \mathrm{mV}$, in the wake of a 6-min-long depolarization to $-10 \mathrm{mV}$. In general, the increase in temperature tended to destabilize the slow inactivated state. For example, in control, $I_{80} / I_{120}$ was $0.55 \pm$ 0.04 at $35^{\circ} \mathrm{C}$, a slight increase relative to $0.36 \pm 0.025$ at $25^{\circ} \mathrm{C}$. Likewise, in the presence of syntaxin, $I_{80} / I_{120}$ was $0.20 \pm 0.03$ at $35^{\circ} \mathrm{C}$ compared to $0.07 \pm 0.02$ at $25^{\circ} \mathrm{C}$. The most striking difference was seen in the influence of syntaxin on the time course of recovery from slow inactivation at strongly negative potentials. At the higher temperature (Fig. $8 E$ ), syntaxin enforced a slow phase 

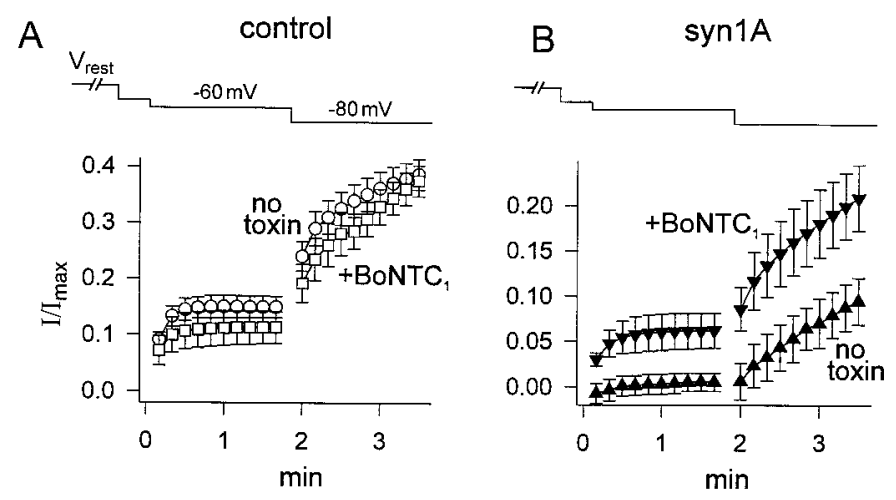

Figure 9. Pretreatment with BoNTC1 decreases effect of syn1A on slow inactivation. Recovery of $I_{\mathrm{Ba}}$ from slow inactivation produced by progressive hyperpolarization of $V_{\mathrm{h}}$ to $-60 \mathrm{mV}$ and then $-80 \mathrm{mV}$, in the absence of syn1A $(A)$, or with syn1A coexpression $(B)$. Test pulses to $+2 \mathrm{mV}$ for $20 \mathrm{msec}$ were applied at $0.1 \mathrm{~Hz}$. Each panel compares recovery without toxin treatment (control, $n=12$; syn1A, $n=9$ ) or after previous injection of oocyte with BoNtC1 light chain (control, $n=9$; $\operatorname{syn} 1 \mathrm{~A}, n=9$ ). Slow inactivation had developed at $V_{\text {rest }}$.

of recovery that was hardly present, if at all, in its absence (Fig. $8 D$ ). In this respect, the relative impact of syntaxin regulation would be more significant at mammalian physiological temperature.

\section{Syntaxin effect decreased by pretreatment with BoNtC1}

Botulinum toxin $\mathrm{C} 1$ (BoNtC1) is known to cleave syntaxin $1 \mathrm{~A}$ at a specific site close to its point of membrane attachment, thereby removing the intracellular $\mathrm{N}$-terminal segment and leaving little more than the $\mathrm{C}$-terminal membrane spanning region (Blasi et al., 1993). This not only eliminates neurotransmitter release but also impairs interaction with $\mathrm{N}$-type $\mathrm{Ca}^{2+}$ channels as studied biochemically (Sheng et al., 1994). Thus, treatment with BoNtC1 represented a critical test of whether the effect of syntaxin on $\mathrm{Ca}^{2+}$ channel inactivation was specific to the intact protein, in accordance with previous work.

In most of the experiments, BoNtC1 was introduced by direct injection into oocytes. The reduced form of the toxin (BoNtC1 light chain) was prepared by incubating the parent molecule with DTT, made up to a pipette concentration of $100 \mathrm{~nm}$, then injected into oocytes 3-6 hr before current recordings to achieve a final concentration of $\sim 1 \mathrm{~nm}$. Recovery from slow inactivation was studied with a hyperpolarizing staircase protocol (from -60 to -80 to $-120 \mathrm{mV}$ ) during the first run after a prolonged period of membrane depolarization (resting potential between -15 and $-25 \mathrm{mV}$ ). In the absence of authentic syntaxin, BoNtC1 treatment had no significant effect on N-type channel availability (Fig. $9 A$ ), the $I_{80} / I_{120}$ being $\sim 0.4$ in both cases. Coexpression of syn1A reduced the $I_{80} / I_{120}$ ratio to $0.09 \pm 0.03(n=4)$. In this case, previous intracellular injection of toxin light chain $(10 \mathrm{~nm}) \mathrm{re}-$ stored the ratio to $0.20 \pm 0.04(n=5)$, a significant increase. In contrast, heat-inactivated BoNtC1 left the ratio unchanged (data not shown).

The partial reversal of the modulatory effect of syntaxin would make sense if BoNTC1 cleaved the bulk of the syntaxin but left some intact. The small surface-to-volume ratio of the oocytes precluded a direct determination of the full-length syntaxin that remained after toxin treatment. Nonetheless, the present experiments provided sufficient encouragement to use BoNTC1 as a
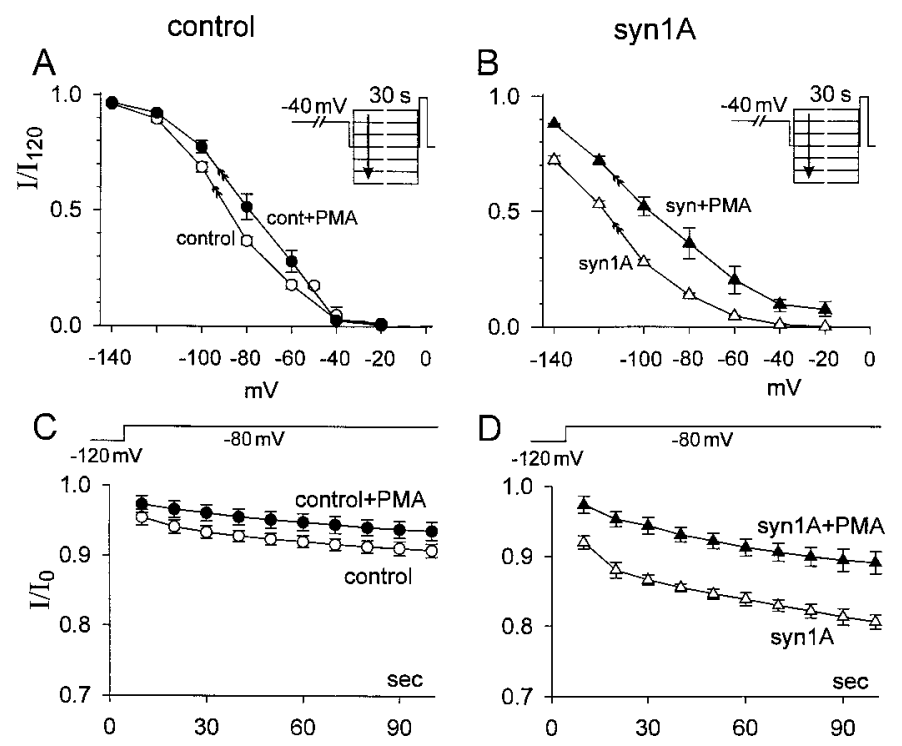

Figure 10. PMA modulates effect of syn1A on slow inactivation. $A, B$, Availability curves, showing recovery from previous inactivation of $I_{\mathrm{Ba}}$ in the absence $(A)$ and presence of syn1A $(B)$, measured with a series of descending voltage steps every $30 \mathrm{sec}(\mathrm{Fig}$. $6 D)$ ). Effect of $10 \mathrm{~min}$ pretreatment with 100 nM PMA ( filled symbols) relative to control. Control $(n=$ $11)$, cont + PMA $(n=7)$, syn1A $(n=5)$, syn + PMA $(n=3)$. $C, D$, Development of slow inactivation during moderate depolarization of $V_{\mathrm{h}}$ (protocol shown above). Trains of test pulses to $+2 \mathrm{mV}$ for $20 \mathrm{msec}$ were applied at $0.1 \mathrm{~Hz}$. $C$, Control $(n=8)$, control + PMA $(n=6) ; D$, syn1A $(n=5)$, and syn + PMA $(n=5)$.

tool to look for possible involvement of syntaxin in nerve terminals (Bergsman and Tsien, 2000).

\section{Modulation of syntaxin effect by stimulation of protein kinase C}

Phosphorylation of the "synprint" site on the II-III loop of $\alpha_{1 \mathrm{~B}}$ by protein kinase $\mathrm{C}$ (PKC) or calmodulin-dependent kinase II has been shown to inhibit binding of syntaxin (Yokoyama et al., 1997). This prompted us to test whether stimulation of PKC might interfere with the ability of syn1A to modify N-type channel inactivation. To stimulate PKC, oocytes were treated with the phorbol ester PMA for $10 \mathrm{~min}$ in $\mathrm{Ca}^{2+}$-containing ND96 medium, then transferred into $5 \mathrm{mM} \mathrm{Ba}^{2+}$ recording solution containing PMA for measurements of $I_{\mathrm{Ba}}$. The analysis described here was restricted to data acquired within 10-30 min of treatment with PMA, to avoid complex changes in $\mathrm{Ca}^{2+}$ channel behavior, including inhibition and irreversible loss of channel activity, known to occur during more prolonged exposure to this agent.

Figure 10 illustrates the effect of PMA on inactivation properties, both in the absence $(A, C)$ and presence $(B, D)$ of syntaxin. Isochronal inactivation curves were measured with $30 \mathrm{sec}$ prepulses to progressively more negative levels, emphasizing the voltage dependence of recovery from inactivation. PMA caused a pronounced displacement of the midpoint voltage in the presence of syntaxin, averaging $20 \pm 6 \mathrm{mV}$ (Fig. 10B), in considerable excess of the midpoint shift in the absence of syntaxin, $9.7 \pm 4.5$ $\mathrm{mV}$ (Fig. 10A). Another way of expressing the effect of PMA is to focus on the hysteresis between inactivation curves obtained with prepulses applied in ascending and descending order, which was greatly enlarged in the presence of syntaxin and largely restored to control values by PMA (data not shown). 
Figure 10, $C$ and $D$, illustrates the influence of PMA on the development of slow inactivation with a depolarization to -80 $\mathrm{mV}$, within the physiological range of membrane potentials. PMA reduced the mild degree of slow inactivation in the absence of syntaxin (C), but exerted a much more dramatic effect on the larger inactivation promoted by syntaxin (D). Once again, stimulation of PKC appears to counteract the inactivation-promoting influence of syntaxin, over and above any influence of PKC on inactivation properties in the absence of syntaxin (Stea et al., 1995).

\section{No effect of lowering cytoplasmic $\mathrm{Ca} 2+$ concentration on the modulatory action of syntaxin}

Syntaxin binds to the intracellular II-III loop of $\alpha_{1 \mathrm{~B}}$ in a $\mathrm{Ca}^{2+}$ dependent manner in experiments in vitro (Sheng et al., 1996). Thus, it was of interest to check whether changes in free intracellular $\mathrm{Ca}^{2+}$ concentration $\left(\left[\mathrm{Ca}^{2+}\right]_{\mathrm{i}}\right)$ might affect syn1A modulation of $\mathrm{Ca}^{2+}$ channel gating. Increases in $\left[\mathrm{Ca}^{2+}\right]_{\mathrm{i}}$ are problematic in Xenopus oocytes because of large $\mathrm{Ca}^{2+}$-activated currents. We restricted our experiments, therefore, to changes in $\left[\mathrm{Ca}^{2+}\right]_{\mathrm{i}}$ below the physiological level by means of buffer injection. BAPTA (50 mM, $50 \mathrm{nl}$ ) was injected preceding the electrophysiological recordings by $10 \mathrm{~min}$ up to a few hours. This intervention failed to produce any significant change in the effect of syntaxin at the resting membrane potential of the oocyte (assessed with the first measurement of $I_{80} / I_{120}$ after initiation of voltage-clamp control). Likewise, we were unable to detect any change in the kinetics of stabilization of slow inactivation as promoted by syntaxin at $-40 \mathrm{mV}$ (data not shown). Further experiments would be needed to determine whether buffering of $\left[\mathrm{Ca}^{2+}\right]_{i}$ in the range of $20 \mu \mathrm{M}$ would alter the modulatory effect of syntaxin.

\section{DISCUSSION}

This study provides a detailed description of the kinetic aspects of syntaxin-mediated modulation of $\mathrm{N}$-type channels, clarifying and extending the original description of this modulation (Bezprozvanny et al., 1995; Wiser et al., 1996). We found that syntaxin greatly accentuated slow inactivation of $\mathrm{N}$-type $\mathrm{Ca}^{2+}$ channels without producing any detectable change in fast inactivation. The specificity of syntaxin effects for slow inactivation was clearly seen with either trains of depolarizing pulses or weak depolarizations, in a range of potentials bracketing the resting potential in neurons. In contrast to slow inactivation, neither rates of decay nor steady-state properties of fast inactivation were significantly affected by syntaxin at any membrane potential over a wide range. The analysis delineated biophysical conditions which most clearly revealed the influence of syntaxin and provided a starting point for understanding its molecular determinants (Bezprozvanny et al., 2000). Our experiments also indicated that the modulatory action of syntaxin could be counteracted by acute treatment with phorbol esters or by pretreatment with the syntaxin-cleaving neurotoxin BoNtC1. The demonstrated effectiveness of BoNtC1 sets the stage for using this toxin to test for possible effects of syntaxin on $\mathrm{Ca}^{2+}$ channels in nerve terminals (Bergsman and Tsien, 2000).

\section{Possible sources of variability in observing syntaxin modulation}

Our results are relevant to apparent discrepancies in the literature about the possible modulatory effect of syntaxin on high voltageactivated $\mathrm{Ca}^{2+}$ channels in neurons. The inhibitory influence of syntaxin on $\mathrm{Ca}^{2+}$ channels has been observed in experiments in Xenopus oocytes (Bezprozvanny et al., 1995; Wiser et al., 1996),
Aplysia neurons (Smirnova et al., 1995), HEK 293 cells (Sutton et al., 1999), and rat cerebrocortical synaptosomes (Bergsman and Tsien, 2000). On the other hand, properties of $\mathrm{N}$ - or P-type $\mathrm{Ca}^{2+}$ channels were not significantly affected by attempts at disrupting their interaction with syntaxin in rat superior cervical ganglion cells subjected to BoNtC1 treatment or injection of synprint peptide (Mochida et al., 1995, 1996), in calyx terminals at chick ciliary ganglion synapses treated with BoNtC1 (Stanley and Mirotznik, 1997), and in squid giant terminals treated with BoNtC1 or anti-syntaxin antibodies (Marsal et al., 1997; Sugimori et al., 1998).

Possible explanations for these discrepancies can be suggested on the basis of this study and the synaptosome experiments of Bergsman and Tsien (2000). First, finding that the syntaxin modulation is specific for slow rather than fast inactivation draws attention to the experimental procedure, which must allow enough time for the slow inactivated state to develop. Prepulses of a few seconds, as used in the published studies with negative findings, might not be long enough to support a significant effect (Fig. 6A). Second, in the case of recordings of N-type currents in sympathetic neuron cell bodies, it is not clear whether syntaxin was present in sufficient quantity to generate a significant inhibition. Third, in nerve terminal preparations where syntaxin is likely to be abundant, the inhibitory effect might be tonically prevented by interactions with other synaptic proteins (Umbach et al., 1998; Nie et al., 1999; Bezprozvanny et al., 2000). Observing a syntaxin effect might require a sufficient degree of vesicular turnover (Bergsman and Tsien, 2000). Fourth, some discrepancies might arise from differences in subunit isotypes or splice variants, as exemplified by $\alpha_{1 \mathrm{~A}}$-encoded $\mathrm{P} / \mathrm{Q}$-type $\mathrm{Ca}^{2+}$ channels that lack the syntaxin-binding synprint motif in their II-III linker (Rettig et al., 1996) as opposed to other splice variants (Sutton et al., 1999). In other cases, splice variations may restrict the ability of channels to visit the slow inactivated state under the existing experimental protocols. In contrast to the $\alpha_{1 \mathrm{~B}} \beta_{3} \alpha_{2}$-based channels that we studied, the N-type channels in sympathetic neurons and chick calyx terminals and the P-type channels in squid giant terminals inactivated relatively slowly, and only with strong depolarizations (Llinas et al., 1981; Stanley and Cox, 1991; Yawo and Chuhma, 1994). If the possibility of syntaxin modulation were reexamined in these systems, it would be interesting to apply trains of pulses to promote hidden inactivation (Patil et al., 1998) because this seems to be particularly effective in supporting the syntaxin effect (Fig. 7).

\section{Selective enhancement by syntaxin of particular aspects of $\mathrm{Ca}^{2+}$ channel inactivation}

Table 1 summarizes the main points of contrast between fast and slow inactivation of $\mathrm{N}$-type $\mathrm{Ca}^{2+}$ channels. As in earlier work (Jones and Marks, 1989), these processes were readily distinguished by large differences in speed of onset and recovery (hundreds of milliseconds vs tens of seconds or minutes). Fast and slow inactivation also showed significantly different steady-state voltage dependence. Slow inactivation became half-maximal at considerably more negative membrane potentials (approximately $-65 \mathrm{mV}$ ) than fast inactivation (approximately $-50 \mathrm{mV}$ ) (Fig. $2 B$ ). These forms of inactivation also differed in how their rate of development varied with membrane depolarization. The onset rate of fast inactivation was a bell-shaped function of membrane potential (Fig. $1 C$ ), whereas the rate of slow inactivation increased monotonically with depolarization, following an S-shaped function of membrane potential that saturated above 


\begin{tabular}{ll}
\hline Table 1. Contrasting properties of fast and slow inactivation of $\mathbf{N}-$ type $\mathbf{C a}^{2+}$ channels \\
Fast inactivation & Slow inactivation \\
\hline Rapidly developing, rapidly recovering & Slowly developing, slowly recovering \\
Less negative voltage midpoint & More negative voltage midpoint \\
Rate voltage-dependent over wide range of & Rate voltage-independent beyond levels where \\
membrane potentials & fast inactivation is saturated \\
Temperature-dependent & Onset not intrinsically temperature-dependent; \\
& recovery strongly temperature-dependent \\
Onset accelerated by repetitive pulsing & Onset accelerated by repetitive pulsing \\
Unaffected by syntaxin & Strongly promoted by syntaxin \\
\hline
\end{tabular}

$-40 \mathrm{mV}$ (Fig. 5D). Temperature dependence represented yet another contrast. Fast inactivation was accelerated more than fourfold with a $10^{\circ} \mathrm{C}$ increase in temperature, but the limiting rate of development of slow inactivation was not increased (Fig. $8 B, C)$.

The finding that an agent, syntaxin, can act selectively on a specific aspect of inactivation gating is novel for $\mathrm{Ca}^{2+}$ channels. Previous descriptions of $\mathrm{Ca}^{2+}$-channel blocking actions of dihydropyridines (Bean, 1984), phenylalkylamines (Striessnig et al., 1998) and $\omega$-conotoxins (Stocker et al., 1997) have invoked preferential interactions with inactivated as opposed to resting states (Hille, 1992), but did not extend the distinction to various forms of inactivation. Whether these well known blockers actually discriminate between fast and slow inactivated states remains to be seen. Our experiments suggest that the multiple phases of inactivation of $\mathrm{Ca}^{2+}$ channel are not only kinetically distinct, but may also be differentially coupled to a putative cellular signaling pathway.

Although slow inactivation is a nearly universal feature of voltage-gated channels, including $\mathrm{Na}^{+}$and $\mathrm{K}^{+}$channels, not much is known for sure about its molecular nature or the relationship between fast and slow inactivated states. Slow inactivation of N-type $\mathrm{Ca}^{2+}$ channels is accompanied by a striking increase in affinity for externally acting $\omega$-conotoxins (Stocker et al., 1997). Useful parallels may be drawn with sodium channels, in which slow inactivation is influenced by changes in external pore residues (Balser et al., 1996; Bénitah et al., 1999) and by external monovalent cations (Townsend and Horn, 1997). Although no modulatory agent has yet been found to act specifically on slow inactivation of $\mathrm{Na}^{+}$channels, this process is selectively altered in disease states such as hyperkalemic periodic paralysis (Cummins and Sigworth, 1996; Hayward et al., 1999). Thus, in both $\mathrm{Na}^{+}$and $\mathrm{Ca}^{2+}$ channels, modifications in slow inactivation can occur without significant variation in fast inactivation.

It is difficult to delineate the detailed relationship between the kinetic states that underlie fast and slow inactivation because transitions between them are electrically silent and must be monitored indirectly. However, our results provided some useful hints. Slow inactivation reached a saturating rate beyond $-40 \mathrm{mV}$ (Fig. 5), mirroring the steady-state occupancy of the fast inactivated state $\left(1 \mathrm{hr}_{\infty}\right)$, which also follows an $\mathrm{S}$-shaped voltage dependence that reaches maximum above $-40 \mathrm{mV}$ (Fig. 6). The simplest interpretation is that the voltage dependence of slow inactivation reflects a coupling to the fast inactivated state, whose occupancy is in quasiequilibrium during the very slow transition to slow inactivation. The lack of intrinsic voltage dependence and the temperature independence of the saturating rate would be consistent with a rate-limiting process that occurs without influ- ence of the transmembrane potential, for example, the diffusionlimited arrival of a modifier or subdomain through cytoplasmic or intramembranous routes. The hypothetical rate-limiting diffusion-like process could be followed by a rapid binding step with high temperature dependence. Removal of inactivation could take place in the opposite order, with dissociation of the effector as a rate-limiting first step with high temperature dependence (Fig. 8D). Whether or not this particular scenario holds true, one can readily imagine that steps leading to slow inactivation might be modulated by syntaxin, which possesses both cytoplasmic and intramembranous domains (Bezprozvanny et al., 2000).

Although fast and slow inactivated states appear to be connected, the link need not be a direct one. The smoothly graded slowing of the time course of recovery as the conditioning pulse is prolonged (Fig. 5) raises the possibility of one or more additional states that support development and recovery from inactivation at intermediate speeds (Nuss et al., 1996). Intermediate states of inactivation would help account for an apparent discrepancy between our results and those of D. Atlas and colleagues (Wiser et al., 1996), who reported that syntaxin caused a twofold slowing in the inactivation of $\mathrm{N}$-type channel. We also found that syntaxin retarded an intermediate phase of inactivation that became obvious at strong depolarizations (Fig. 2, bottom right), although it is still unclear what this implies for the various forms of inactivation and their underlying kinetic states.

\section{Functional implications}

Two hypotheses, not mutually exclusive, can be put forward for how the modulatory effect of syntaxin might be functionally relevant to $\mathrm{Ca}^{2+}$ channel activity in situ. The first and more familiar hypothesis is that syntaxin acts at sites of neurotransmission, as part of a signaling apparatus linked to the present condition or past history of vesicular turnover (Gundersen and Umbach, 1992; Bezprozvanny et al., 1995; Wiser et al., 1996; Nie et al., 1999). The issue of whether syntaxin affects $\mathrm{Ca}^{2+}$ influx in nerve terminals and how it might depend on the state of the release machinery will be taken up in a subsequent paper (Bergsman and Tsien, 2000).

Another possibility is that syntaxin can act outside the nerve terminal, independent of its activity as a $t$-SNARE. Syntaxin is abundantly expressed on neuronal cell bodies and dendrites (Galli et al., 1995) along with $\mathrm{Ca}^{2+}$ channels. Regulation of somatic or dendritic $\mathrm{Ca}^{2+}$ influx would be consistent with the ability of syntaxin to modulate the activity of other membrane transport proteins, including the CFTR chloride channel (Naren et al., 1997, 1998), norepinephrine transporters (Apparsundaram et al., 1998), and a GABA transporter (Beckman et al., 1998). 
Syntaxin has also been shown to affect neuronal survival, independent of its effect on secretion (Osen-Sand et al., 1996; Williamson and Neale, 1998). Recent experiments suggest that syntaxin might be involved in a negative feedback signaling system involving somatic P/Q-type channels and regulated gene expression in cerebellar neurons (Sutton et al., 1999).

Clarification of the kinetic aspects of the syntaxin effect is highly relevant to how such modulation might operate in either synaptic or extrasynaptic settings. In both cases, the syntaxindependent build-up of slow inactivation could result from steady depolarizations near the neuronal resting potential or trains of action-potentials. Syntaxin-dependent slowing of exit from the slow inactivated state would be particularly striking at physiological temperature. The use-dependent inhibition of voltage-gated $\mathrm{Ca}^{2+}$ entry would operate over a time scale of min, a time scale pertinent to stimuli that evoke long-lasting neuronal modifications through changes in synaptic or nuclear activity. Spatial specificity of the modulation might arise from cellular localization of syntaxin or of molecules that interfered with its inhibitory action. These possibilities take on particular interest in light of recent recordings from presynaptic P-type channels at a calyx synapse in the brainstem (Forsythe et al., 1998). Trains of brief pulses or conventional depolarizing pulses produced long-lasting inactivation of these channels, which required 1-2 min for full recovery, with clear dependence on divalent cation entry.

Our experiments also provided evidence that activated PKC can interfere with the ability of syntaxin to promote slow inactivation. These results might be related to the finding that phosphorylation of the "synprint" site of $\mathrm{Ca}^{2+}$ channel fragments inhibited their interaction with SNARE proteins (Yokoyama et al., 1997). In addition to direct phosphorylation of channel subunits themselves (Stea et al., 1995), the modulation of syntaxin effect on $\mathrm{Ca}^{2+}$ channels may be a factor contributing to the well known actions of PKC on $\mathrm{Ca}^{2+}$ channel activity (Yang and Tsien, 1993) and neurotransmitter release (Parfitt and Madison, 1993). It is intriguing to consider that very much as $\mathrm{PKC}$ regulates G-protein inhibition of $\mathrm{Ca}^{2+}$ channels on a time scale of milliseconds (Swartz, 1993; Zamponi et al., 1997), this protein kinase might also modulate the inhibitory effect of syntaxin over periods of many seconds or longer.

\section{REFERENCES}

Apparsundaram S, Sung U, Kendall D, Blakely RD (1998) Regulated association of syntaxin I with norepinephrine transporters. 28th Annual Meeting of the Society for Neuroscience,.

Balser JR, Nuss HB, Chiamvimonvat N, Pérez-García MT, Marban E, Tomaselli GF (1996) External pore residue mediates slow inactivation in mu 1 rat skeletal muscle sodium channels. J Physiol (Lond) 494:431-442.

Bean BP (1984) Nitrendipine block of cardiac calcium channels: high affinity binding to the inactivated state. Proc Natl Acad Sci USA 81:6388-6392.

Beckman ML, Bernstein EM, Quick MW (1998) Protein kinase C regulates the interaction between a GABA transporter and syntaxin 1A. J Neurosci 18:6103-6112.

Bénitah JP, Chen Z, Balser JR, Tomaselli GF, Marbán E (1999) Molecular dynamics of the sodium channel pore vary with gating: interactions between P-segment motions and inactivation. J Neurosci 19:1577-1585.

Bennett MK, Calakos N, Scheller RH (1992) Syntaxin: a synaptic protein implicated in docking of synaptic vesicles at presynaptic active zones. Science 257:255-259.

Bergsman JB, Tsien RW (1996) Testing for botulinum toxin type C1 effect on calcium flux in rat neocortical synaptosomes. J Gen Physiol 108:.

Bergsman JB, Tsien RW (2000) Syntaxin modulation of calcium chan- nels in cortical synaptosomes as revealed by botulinum toxin C1. J Neurosci 20:4368-4378.

Bezprozvanny I, Scheller RH, Tsien RW (1995) Functional impact of syntaxin on gating of N-type and Q-type calcium channels. Nature 378:623-626.

Bezprozvanny IB, Zhong P, Scheller RH, Tsien RW (2000) Molecular determinants of the functional interaction between syntaxin and $\mathrm{N}$-type $\mathrm{Ca}^{2+}$ channel gating, in press.

Blasi J, Chapman ER, Yamasaki S, Binz T, Niemann H, Jahn R (1993) Botulinum neurotoxin $\mathrm{C} 1$ blocks neurotransmitter release by means of cleaving HPC-1/syntaxin. EMBO J 12:4821-4828.

Castillo PE, Weisskopf MG, Nicoll RA (1994) The role of Ca2+ channels in hippocampal mossy fiber synaptic transmission and long-term potentiation. Neuron 12:261-269.

Cox DH, Dunlap K (1994) Inactivation of N-type calcium current in chick sensory neurons: calcium and voltage dependence. J Gen Physiol 104:311-336.

Cummins TR, Sigworth FJ (1996) Impaired slow inactivation in mutant sodium channels [see comments]. Biophys J 71:227-236.

DeBello WM, O'Connor V, Dresbach T, Whiteheart SW, Wang SS, Schweizer FE, Betz H, Rothman JE, Augustine GJ (1995) SNAPmediated protein-protein interactions essential for neurotransmitter release. Nature 373:626-630.

Degtiar VE, Bergsman JB, Scheller RH, Tsien RW (1997) Botulinum toxin $\mathrm{C}$ interferes with putative syntaxin regulation of $\mathrm{Ca}^{2+}$ channel activity oocytes and synaptosomes. Soc Neurosci Abstr 23:.

Douglas WW (1968) Stimulus-secretion coupling: the concept and clues from chromaffin and other cells. Br J Pharmacol 34:453-474.

Ellinor PT, Zhang J-F, Horne WA, Tsien RW (1994) Structural determinants of the blockade of N-type calcium channels by a peptide neurotoxin. Nature 372:272-275.

Forsythe ID, Tsujimoto T, Barnes-Davies M, Cuttle MF, Takahashi T (1998) Inactivation of presynaptic calcium current contributes to synaptic depression at a fast central synapse. Neuron 20:797-807.

Galli T, Garcia EP, Mundigl O, Chilcote TJ, De Camilli P (1995) v- and t-Snares in neuronal exocytosis: a need for additional components to define sites of release. Neuropharmacology 34:1351-1360.

Gundersen CB, Umbach JA (1992) Suppression cloning of the cDNA for a candidate subunit of a presynaptic calcium channel. Neuron 9:527-537.

Hanson PI, Heuser JE, Jahn R (1997) Neurotransmitter release - four years of SNARE complexes. Curr Opin Neurobiol 7:310-315.

Hayward LJ, Sandoval GM, Cannon SC (1999) Defective slow inactivation of sodium channels contributes to familial periodic paralysis [see comments]. Neurology 52:1447-1453.

Hille B (1992) Ionic channels of excitable membranes, Ed 2. Sunderland, MA: Sinauer.

Hullin R, Singer-Lahat D, Freichel M, Biel M, Dascal N, Hofmann F, Flockerzi V (1992) Calcium channel $\beta$ subunit heterogeneity: functional expression of cloned cDNA from heart, aorta and brain. EMBO J 11:885-890.

Jones SW, Marks TN (1989) Calcium currents in bullfrog sympathetic neurons. II. Inactivation. J Gen Physiol 94:169-182.

Kasai H, Aosaki T (1988) Divalent cation dependent inactivation of the high-voltage-activated $\mathrm{Ca}$-channel current in chick sensory neurons. Pflügers Arch 411:695-697.

Katz B (1969) The release of neural transmitter substances. Liverpool: Liverpool UP.

Katz B, Miledi R (1965) The effect of calcium on acetylcholine release from motor nerve terminals. Proc R Soc Lond B Biol Sci 161:496-503.

Leveque C, el Far O, Martin-Moutot N, Sato K, Kato R, Takahashi M, Seagar MJ (1994) Purification of the N-type calcium channel associated with syntaxin and synaptotagmin. A complex implicated in synaptic vesicle exocytosis. J Biol Chem 269:6306-6312.

Llinas R, Steinberg IZ, Walton K (1981) Presynaptic calcium currents in squid giant synapse. Biophys J 33:289-321.

Marsal J, Ruiz-Montasell B, Blasi J, Moreira JE, Contreras D, Sugimori M, Llinás R (1997) Block of transmitter release by botulinum C1 action on syntaxin at the squid giant synapse. Proc Natl Acad Sci USA 94:14871-14876.

Mastrogiacomo A, Parsons SM, Zampighi GA, Jenden DJ, Umbach JA, Gundersen CB (1994) Cysteine string proteins: a potential link between synaptic vesicles and presynaptic $\mathrm{Ca}^{2+}$ channels. Science 263:981-982.

Mochida S, Saisu H, Kobayashi H, Abe T (1995) Impairment of syntaxin 
by botulinum neurotoxin $\mathrm{C} 1$ or antibodies inhibits acetylcholine release but not $\mathrm{Ca} 2+$ channel activity. Neuroscience 65:905-915.

Mochida S, Sheng ZH, Baker C, Kobayashi H, Catterall WA (1996) Inhibition of neurotransmission by peptides containing the synaptic protein interaction site of N-type $\mathrm{Ca}^{2+}$ channels. Neuron 17:781-788.

Naren AP, Nelson DJ, Xie W, Jovov B, Pevsner J, Bennett MK, Benos DJ, Quick MW, Kirk KL (1997) Regulation of CFTR chloride channels by syntaxin and Munc18 isoforms. Nature 390:302-305.

Naren AP, Quick MW, Collawn JF, Nelson DJ, Kirk KL (1998) Syntaxin 1A inhibits CFTR chloride channels by means of domain-specific protein-protein interactions. Proc Natl Acad Sci USA 95:10972-10977.

Nie Z, Ranjan R, Wenniger JJ, Hong SN, Bronk P, Zinsmaier KE (1999) Overexpression of cysteine-string proteins in Drosophila reveals interactions with syntaxin. J Neurosci 19:10270-10279.

Nuss HB, Balser JR, Orias DW, Lawrence JH, Tomaselli GF, Marban E (1996) Coupling between fast and slow inactivation revealed by analysis of a point mutation $(\mathrm{F} 1304 \mathrm{Q})$ in mu 1 rat skeletal muscle sodium channels. J Physiol (Lond) 494:411-429.

Osen-Sand A, Staple JK, Naldi E, Schiavo G, Rossetto O, Petitpierre S, Malgaroli A, Montecucco C, Catsicas S (1996) Common and distinct fusion proteins in axonal growth and transmitter release. J Comp Neurol 367:222-234.

Parfitt KD, Madison DV (1993) Phorbol esters enhance synaptic transmission by a presynaptic, calcium-dependent mechanism in rat hippocampus. J Physiol (Lond) 471:245-268.

Patil PG, Brody DL, Yue DT (1998) Preferential closed-state inactivation of neuronal calcium channels. Neuron 20:1027-1038.

Rettig J, Sheng ZH, Kim DK, Hodson CD, Snutch TP, Catterall WA (1996) Isoform-specific interaction of the alpha1A subunits of brain $\mathrm{Ca}^{2+}$ channels with the presynaptic proteins syntaxin and SNAP-25. Proc Natl Acad Sci USA 93:7363-7368.

Sheng ZH, Rettig J, Takahashi M, Catterall WA (1994) Identification of a syntaxin-binding site on N-type calcium channels. Neuron 13:1303-1313.

Sheng ZH, Rettig J, Cook T, Catterall WA (1996) Calcium-dependent interaction of $\mathrm{N}$-type calcium channels with the synaptic core complex. Nature 379:451-454.

Smirnova T, Fossier P, Stinnakre J, Mallet J, Baux G (1995) A syntaxinrelated protein controls acetylcholine release by different mechanisms in Aplysia. Neuroscience 68:125-133.

Stanley EF, Cox C (1991) Calcium channels in the presynaptic nerve terminal of the chick ciliary ganglion giant synapse. Ann NY Acad Sci 635:70-79.

Stanley EF, Mirotznik RR (1997) Cleavage of syntaxin prevents G-protein regulation of presynaptic calcium channels. Nature 385:340-343.

Stea A, Soong TW, Snutch TP (1995) Determinants of PKC-dependent modulation of a family of neuronal calcium channels. Neuron 15:929-940.

Stocker JW, Nadasdi L, Aldrich RW, Tsien RW (1997) Preferential interaction of omega-conotoxins with inactivated $\mathrm{N}$-type $\mathrm{Ca}^{2+}$ channels. J Neurosci 17:3002-3013.
Striessnig J, Grabner M, Mitterdorfer J, Hering S, Sinnegger MJ, Glossmann H (1998) Structural basis of drug binding to $\mathrm{L} \mathrm{Ca}^{2+}$ channels. Trends Pharmacol Sci 19:108-115.

Sudhof TC (1995) The synaptic vesicle cycle: a cascade of proteinprotein interactions. Nature 375:645-653.

Sugimori M, Tong CK, Fukuda M, Moreira JE, Kojima T, Mikoshiba K, Llinás R (1998) Presynaptic injection of syntaxin-specific antibodies blocks transmission in the squid giant synapse. Neuroscience 86:39-51.

Sutton K, McRory J, Guthrie H, Snutch T (1999) Ca influx through $\mathrm{P} / \mathrm{Q}$-type $\mathrm{Ca}$ channels mediates syntaxin-1A gene transcription. $\mathrm{Br}$ Neurosci Assoc Abstr 15:57.

Swartz KJ (1993) Modulation of $\mathrm{Ca}^{2+}$ channels by protein kinase $\mathrm{C}$ in rat central and peripheral neurons: disruption of $\mathrm{G}$ protein-mediated inhibition. Neuron 11:305-320.

Takahashi T, Momiyama A (1993) Different types of calcium channels mediate central synaptic transmission. Nature 366:156-158.

Townsend C, Horn R (1997) Effect of alkali metal cations on slow inactivation of cardiac $\mathrm{Na}+$ channels. J Gen Physiol 110:23-33.

Turner TJ, Adams ME, Dunlap K (1993) Multiple Ca2+ channel types coexist to regulate synaptosomal neurotransmitter release. Proc Natl Acad Sci USA 90:9518-9522.

Turner TJ, Lampe RA, Dunlap K (1995) Characterization of presynaptic calcium channels with omega-Conotoxin MVIIC and omegagrammotoxin SIA: role for a resistant calcium channel type in neurosecretion. Mol Pharmacol 47:348-353.

Umbach JA, Saitoe M, Kidokoro Y, Gundersen CB (1998) Attenuated influx of calcium ions at nerve endings of csp and shibire mutant Drosophila. J Neurosci 18:3233-3240.

Wheeler DB, Randall A, Tsien RW (1994) Roles of N-type and Q-type $\mathrm{Ca}^{2+}$ channels in supporting hippocampal synaptic transmission. Science 264:107-111.

Williamson LC, Neale EA (1998) Syntaxin and 25-kDa synaptosomalassociated protein: differential effects of botulinum neurotoxins $\mathrm{C} 1$ and A on neuronal survival. J Neurosci Res 52:569-583.

Wiser O, Bennett MK, Atlas D (1996) Functional interaction of syntaxin and SNAP-25 with voltage-sensitive $\mathrm{L}$ - and $\mathrm{N}$-type $\mathrm{Ca} 2+$ channels. EMBO J 15:4100-4110.

Yang J, Tsien RW (1993) Enhancement of N- and L-type calcium channel currents by protein kinase $\mathrm{C}$ in frog sympathetic neurons. Neuron 10:127-136.

Yawo H, Chuhma N (1994) $\omega$-Conotoxin-sensitive and -resistant transmitter release from the chick ciliary presynaptic terminal. J Physiol (Lond) 477:437-448.

Yokoyama CT, Sheng ZH, Catterall WA (1997) Phosphorylation of the synaptic protein interaction site on N-type calcium channels inhibits interactions with SNARE proteins. J Neurosci 17:6929-6938.

Yoshida A, Oho C, Omori A, Kuwahara R, Ito T, Takahashi M (1992) HPC-1 is associated with synaptotagmin and omega-Conotoxin receptor. J Biol Chem 267:24925-24928.

Zamponi GW, Bourinet E, Nelson D, Nargeot J, Snutch TP (1997) Crosstalk between $\mathrm{G}$ proteins and protein kinase $\mathrm{C}$ mediated by the calcium channel alpha1 subunit [see comments]. Nature 385:442-446. 